\title{
JUAN BAUTISTA PEROLLI. OBRAS GENOVESAS. I
}

\author{
POR \\ ROSA LÓPEZ TORRIJOS \\ Universidad de Alcalá
}

Juan Bautista Perolli is the most known between Genoese artists working in the palace of Viso del Marqués (Ciudad Real). Up to the date very little was known of his work at Genoa and we had only short notices -often wrong ones- about his activity in Spain. In this article some of these mistakes are corrected and it starts on the study of Perolli's complete work, first at Genoa collaborating with J.B. Castello, el Bergamasco. This study will help to later understanding of his participation in the Spanish palace of El Viso.

Uno de los nombres más frecuentemente citados y sin duda el más conocido entre los italianos que trabajaron en el palacio del Viso del Marqués durante el siglo Xvi es Juan Bautista Perolli, a quien se atribuye el papel de director de las obras del palacio durante una larga etapa.

Así pues, es preciso determinar su identidad e individualizar su perfil artístico, para comenzar a conocer a quienes intervinieron en las obras del palacio manchego y para saber lo que corresponde a cada uno. Este es asunto de sumo interés para la historia artística del siglo XvI español, tanto en lo que se refiere a arquitectura como a pintura y decoración en general, dada la importancia que tiene el palacio, tanto desde el punto de vista de estructuras arquitectónicas como de pintura, iconografía y testimonio de las influencias italianas en España.

El hecho de carecer de documentación suficiente y precisa sobre esta obra ${ }^{2}$ y de no haberse emprendido seriamente - por su dificultad - un estudio estilístico de sus componentes, hace que el palacio del Viso del Marqués sea todavía uno de los temas más oscuros de nuestro arte del siglo XvI.

La primera bibliografía española, comenzando por Palomino, cita el apellido Perola y lo aplica a dos hermanos, Juan y Francisco, naturales de Almagro, pintores, escultores y arquitectos, que murieron por los años de 1600 y trabajaron en el Viso, iglesia de Villanueva de los Infantes y Sagrario de la catedral de Córdoba ${ }^{3}$.

\footnotetext{
1 Este trabajo forma parte de un proyecto de investigación financiado por la DGICYT (PB94-0353). En su elaboración me ha sido valiosísima la ayuda recibida de los profesores Elena Parma, Eduardo Grendi y Ennio Poleggi, a quienes quiero manifestar aquí mi gradecimiento.

${ }^{2}$ En el archivo de los marqueses de Santa Cruz se registra en los años 1778 y 1792, un libro independiente titulado «Cuentas de la Fábrica del Palacio de la Villa del Viso, que contiene las cuentas de varios oficiales que trabajaron en la Fabrica del Palacio, que tiene el excmo.sr. Marques de Santa Cruz en la villa del Viso. Año de 1586», sin duda el consultado por Ceán e investigadores posteriores, pero cuyo paradero actual se desconoce, por el momento. (Véase más abajo nota 7).

${ }^{3}$ Palomino de Castro y Velasco, El Museo pictórico y escala óptica,[1724] ed. Madrid 1947, pp. 814-815.
} 
Estos mismos datos fueron recogidos por Ponz, quien además atribuye a los Perolli varias obras de los conventos franciscanos del Viso del Marqués ${ }^{4}$.

Ceán por su parte, habla en su Diccionario, de Juan, Francisco y Estéfano Perola, pintores, los dos primeros hermanos y naturales de Almagro, y el tercero hermano o pariente. El mismo, citando como fuente el archivo del marqués de Santa Cruz, dice que estaban en el palacio en 1586 pintando con César Arbasía y les atribuye igualmente todas las obras citadas por Palomino y Ponz ${ }^{5}$. En sus Adiciones a Llaguno dice Ceán que Juan Bautista Prioli, genovés, era maestro mayor de la obra en $1586^{6}$. Aquí resume también unas notas más amplias recogidas en el volumen VI de su manuscrito de Historia del arte de la Pintura y que han pasado hasta ahora desapercibidas. El manuscrito, conservado en la Real Academia de San Fernando de Madrid, está fechado el 24-12-1824 y en él manifiesta Ceán que «escarmentado de las equivocaciones de Palomino» pidió información al marqués de Santa Cruz y éste a su administrador, quien no encontró noticias en el archivo familiar pero sí remitió algunas extraídas del archivo parroquial de la villa ${ }^{7}$. Estas noticias del archivo parroquial, copiadas por Ceán, se encuentran también entre sus manuscritos conservados en la Academia de San Fernando ${ }^{8}$ y corresponden exactamente con el texto de Viñaza en las Adiciones al Diccionario... de Ceán, de 1894, aunque éste no manifiesta su procedencia. En ellas se habla solo de Juan y Esteban, pintores, italianos, con apellido Cremaso y se da noticia de las velaciones de Juan Bautista Peroli

\footnotetext{
4 Viage de España..., t. XVI, Madrid 1791, p. 54 ss.

${ }_{5}^{5}$ Diccionario histórico de los más ilustres profesores de las Bellas Artes en España Madrid 1800, IV, pp. 85-87.

${ }^{6}$ Llaguno y Amirola, Eugenio, Noticia de los arquitectos y arquitectura de España desde su restauración...ilustrada y acrecentada con notas, adiciones y documentos por D. Juan Agustín Ceán-Bermúdez [Madrid 1829] ed. Madrid 1977, Turner, tomo III, p. 9 , nota 1

${ }^{7}$ El archivo del «Estado de Santa Cruz» se encontraba tradicionalmente en el palacio del Viso y el hecho de que el administrador no encontrara noticia nos hace pensar que por entonces ya habría desaparecido el libro de cuentas de la fábrica del palacio, no obstante, algún legajo al menos debía de existir puesto que el mismo Ceán dice, en las Adiciones a LLaguno, publicadas en 1829 (III n.1.p. 9) que él había visto un legajo de cuentas de gastos de la obra del palacio que le proporcionó el marqués de Santa Cruz. Por su interés copiamos a continuación el párrafo inédito del manuscrito de Ceán: «... y acordándome de lo que yo había visto pintado en el palacio del Viso el año de 1768 siendo muchacho de 18 años, yendo en compañía del Colegial Mayor de San Ildefonso d. Gaspar Melchor de Jove-LLanos joven de 24, que iba a Sevilla nombrado Alcalde del Crimen de aquella Audiencia, formé el artículo de los Perolas para mi Diccionario. Pasado mucho tiempo y después de haberse publicado esta obra volví por la tercera vez a Madrid y escarmentado de los chascos y equivocaciones que me había dado Palomino en su Parnaso... y deseoso de saber con certeza quienes habían sido los Perolas supliqué al actual Sr. Marqués de Santa Cruz tan amable y aficionado a las Bellas Artes como lo fueron su buen padre e ilustres antecesores. Tuvo la bondad S.E. de escribir inmediatamente a su Administrador en el Viso para que no omitiese diligencia alguna a fin de responder a la Nota, que yo había entregado. Por desgracia no encontró el administrador en los papeles de aquel Estado noticia alguna de los artistas que habian construido y pintado el palacio, pero halló en la parroquia de la villa ciertas partidas de bautismo que lo aseguran. Diré lo que de ellas resulta para no molestar al lector, pues son de los hijos de los pintores siguientes Juan Bautista Perolli cremaso, Estevan Peroli cremaso, Maese Pedro, Marcos Antonio y Juan Bautista Passano... El primero residía en el Viso en 1577 que era pintor mayor y albañil principal de la obra del palacio del Sr. Marqués y que corría con la dirección de ella, casado con Jerónima Passano, hermana de Juan Bautista Passano, tuvieron dos hijos y cinco hijas que se bautizaron desde 1577 a 1596 . El segundo era pintor de la obra casado con Hipólita Passano que tuvieron un hijo en 1590 y otro en 1609 , ambos bautizados en la parroquia. El tercero italiano y pintor casado con Francisca Martínez de quien tuvo un hijo que se bautizó el año 1578. El cuarto italiano y pintor casado con Isabel Fernández de la cual tuvo una hija bautizada en 1584. El quinto italiano y pintor del palacio tuvo un hijo en 1585 de su mujer Catalina García. Entre los padrinos se nombra a maestro Domingo y al maestro Alberto también pintores italianos del dicho palacio y todos avencidados en la villa del Viso desde 1577 hasta 1609 . De esto se infiere que estos siete profesores fueron los pintores de los frescos del palacio del Viso y no los que refiere Palomino. Pudieron haber trabajado los sepulcros de mármol que están en la iglesia de las monjas franciscas de aquella villa, haber pintado en la parroquia de la villa de Infantes y haber ayudado a Antonio Mohedano en la pintura al fresco de la capilla del Sagrario de la catedral de Córdoba, como quiere Palomino hayan sido sus Perolas manchegos, quedando los italianos cremoneses [llamada al pie a lápiz: cremasos no cremoneses] residieron en aquella provincia más de treinta años y pudieron haber propagado su estilo y buen gusto en la escuela castellana y andaluza (Ms. 377-387/3 de la Real Academia de Bellas Artes de San Fernando. Vol VI. fol. 94-97).

${ }^{8}$ Ms.38-1/4. Letra P n ${ }^{\circ}$ 42-43. «Perolas. Noticias autenticas de las Partidas de Bautismo y casamientos de estos pintores sacadas del Archivo de la Iglesia Parroquial del Viso, que me comunicó el S.or Marqués de Sta. Cruz».
} 
con Jerónima Passano en 1589, suponiendo un matrimonio previo, ya que sus siete hijos nacen de 1577 a 1596, también da a conocer sus relaciones con Juan Bautista Pasano, pintor igualmente del palacio en 1585. De Esteban Peroli o Cremaso cuenta su matrimonio con Hipólita Passano, el nacimiento de su hija María en 1590, su segundo matrimonio con Juana de Ribadeneyra y el nacimiento de otra hija en 1609, así como sus relaciones con Marcos Antonio, pintor italiano del palacio. No menciona a Francisco ${ }^{9}$. La bibliografía española posterior repite casi exclusivamente lo dicho hasta ahora ${ }^{10}$.

Angulo habla del matrimonio de Juan Bautista en el Viso en 1569 y dice que continuaba viviendo allí en $1596^{11}$, noticias cuya fuente no precisa. A Esteban no lo menciona, pero sí a Francisco hermano de Juan Bautista, dato que creemos toma de Palomino.

Posteriormente se ha podido obtener esporádicamente alguna noticia sobre actividades de Juan Bautista; así por ejemplo, sabemos que a finales de 1581 revisa la traza dada por el hermano Juan García para el colegio de jesuitas de Segura de la Sierra — que no se llegó a construir - ${ }^{12}$ y en 1584 él mismo da la traza para la iglesia de los jesuitas en este lugar ${ }^{13}$.

Más recientemente se han querido distinguir tres Perolli: Battista (activo en Génova con Castello y que estaría en España de 1569 a 1571 regresando a Italia después), Giovanni Battista (documentado en el palacio del Viso de 1577 a 1596) y Stefano, sobrino de éste último ${ }^{14}$.

${ }^{9}$ Adiciones al Diccionario histórico...de D. Juan Agustín Cean Bermúdez Madrid 1894. III p. 256-258. De la exactitud de esta consulta en el archivo parroquial hablaremos más adelante. En el mismo archivo de la Academia se conserva también, una nota firmada por Valentín Carderera, desconocida hasta ahora, y que resume los datos recogidos por Ceán. La nota va encabezada: «Corrigase [sic] el artículo los Perolas de C. Bermúdez», y en ella se indica que los Peroli «se avencidaron en el Viso desde el año 1577 hasta el de 1609, Juan Bautista Peroli (no Perola) cremaso, pintor mayor y albañil principal de la obra y que corría con la dirección de ella (del palacio). Esteban Peroli cremaso, pintor del palacio casado con Hipolita Pasano, ambos italianos, Maese Pedro - italiano también- pintor, Marcos Antonio pintor italiano, Juan Bautista Pasano italiano pintor del Palacio y tubo una hija de su muger Catalina Garcia. De todo lo dicho se infiere que esos 7 [(?), dice siete porque está copiando a Ceán] profesores son los que pintaron en el palacio y no los que refiere Palomino. Extracto de los documentos de casa del Sr. Marqués de Santa Cruz Sr. del Viso. Tengo hecha una descripción detallada de los salones y pinturas de dicho magnifico palacio. V Carderera» (Legado Carderera, 88-2/4). Los documentos de Carderera fueron estudiados por Portela Sandoval («Nuevas Adiciones al «Diccionario» de Ceán Bermúdez», B.S.A.A. (1976), pp. 365-374) pero nada dijo de los Perola.

${ }^{10}$ El archivo del marqués de Santa Cruz fue consultado esporádicamente, como se desprende de los datos anteriores y de otras breves referencias hechas por varios estudiosos en relación a otros italianos, que trabajaron también en el palacio del Viso (algunas de las cuales veremos más adelante). Algunos de ellos pudieron ver cuentas de la fábrica del palacio, actualmente desaparecidas. El segundo archivo citado es el de la parroquia del Viso del Marqués, que nadie había vuelto a consultar para comprobar o ampliar las noticias publicadas por Viñaza. De los libros que se conservan en la parroquia actualmente, interesan para nuestra investigación los de bautismo (1525 (aproximadamente)-1570 y 1575 1598) y los de desposorios (1571-1585 y 1586 en adelante) - los de entierros son posteriores a 1639-. De su consulta se desprenden algunos errores comunicados a Ceán. Con sus datos correctos se obtienen algunas noticias de interés, aunque lógicamente todo corresponde a la etapa española de los Perolli, por lo que quedan para un trabajo posterior. En cualquier caso, el archivo parroquial del Viso del Marqués ha sido consultado y en cierto modo ordenado, por Juan del Campo, investigador viseño, quien ha reunido todas las noticias obtenidas en un trabajo al que haremos referencia posteriormente.

11 «La Mitología y el arte español del Renacimiento», B.R.A.H. T.CXXX (1952), p. 14 y Pintura del Renacimiento, (Ars Hispaniae, vol.XII) Madrid, 1954,.p. 265

12 El Padre Gil González Dávila envía un informe sobre esta obra el 11-2-1582 y entre otras cosas dice: «Hize rever la traza a un principal maestro de obras, natural de Crema, que el marqués de Santa Cruz truxo consigo de Italia. Contentóle y taxóse el edificio en seis o ocho mill ducados de costa» (Rodríguez Gutiérrez de Ceballos, Alfonso, Bartolomé de Bustamante y los orígenes de la arquitectura jesuítica en España, Roma 1967 p. 300, nota 12).

13 Ibidem, p. 301.

14 Bustamante, Agustín y Marías, Fernando, «La estela de El Viso del Marqués: Esteban Perolli» A.E.A. (1982), pp. 173185. Para Battista y su viaje a España con regreso a Génova se basan seguramente en bibliografía italiana, citada más abajo, fundamentalmente en Wilkinson y Caraceni. 
Sobre Esteban, que prolongó su actividad durante muchos años en tierras manchegas, las aportaciones nuevas son mucho mas abundantes ${ }^{15}$ e igualmente hay noticias de otros descendientes de Perolli trabajando en España ya en el siglo XVII ${ }^{16}$.

Finalmente, en 1998, Juan del Campo Muñoz publicó datos obtenidos en el archivo parroquial del Viso del Marqués, corrigiendo errores cometidos anteriormente. Los datos parroquiales hacen referencia a Juan Bautista, Esteban y Juan Esteban Perolli ${ }^{17}$.

En cuanto a la bibliografía italiana (exceptuando los datos documentales genoveses sobre Battista Perolli, a los que nos dedicaremos ampliamente en este estudio), vemos que, si bien no menciona a los Perolli en obras de conjunto sobre artistas, (tipo vidas de artistas, abecedarios, enciclopedias, etc.), sí recoge por el contrario - al menos desde 1753 - a los Perola, considerándolos españoles y mencionando a Juan y Francisco, siguiendo lo dicho por Palomino ${ }^{18}$, o a Juan, Francisco y Esteban, tomando los datos de Ceán ${ }^{19}$.

Todos estos datos mezclados, pero referidos ya a los Perolli italianos, son repetidos después, hasta nuestros días por estudiosos italianos y españoles, hablando de varios Perolli que trabajan en Génova, de dos viajes a España de Battista o de una etapa piamontesa tras su regreso de España ${ }^{20}$.

Esto es brevemente el resumen de las noticias sobre los Perolli en España, datos y estancia, que no son en este momento de nuestro interés, pero que serán valiosos para ayudar a completar el perfil genovés.

A la etapa genovesa de uno de los Perolli, como veremos, va dedicado este estudio, ya que creemos necesario conocer primero su experiencia en Italia para abordar el tema de su participación en la obra española del Viso del Marqués.

En Génova, la figura de Battista Perolli aparece con relativa frecuencia en los documentos del siglo XVI, pero su papel secundario colaborando con grandes maestros, especialmente con el Bergamasco, ha hecho que no se haya prestado atención a su biografía personal, tema que sin embargo es prioritario para aquellos que estudiamos su trabajo en España.

La documentación genovesa se refiere indistintamente a Baptista o Battista de Perolis (Perollis, Perrolis, Periolis, Preyrolis, Perollo, Perolla, Perola) de Crema (cremasco o cremaschi-

\footnotetext{
15 Está probada documentalmente su participación en el retablo de Miguelturra (Ciudad Real) en 1604 (Herrera Maldonado, Enrique, El Barroco, en La provincia de Ciudad Real (III): Arte y Cultura Ciudad Real, 1993, pp. 123-174 y Sainz Magaña, Elena y Herrera Maldonado, Enrique. Arte Moderno en Ciudad Real y su provincia, III Sevilla, 1997 p. 190) y en las obras del convento de San Francisco del Viso desde 1623, siendo ya vecino de Almagro (Bustamante y Marías Ob.cit. p. 175, que se refieren a documentos del archivo del marqués de Santa Cruz, vistos también por Ceán). Además, por razones de estilo se le atribuyen otras obras (Díez de Baldeón, Clementina, Almagro. Arquitectura y sociedad, [Ciudad Real] 1993 y Sainz Magaña, Elena y Herrera Maldonado, Enrique, ob. cit., pp. 168-171). Los autores de esta última publicación recogen todos los Perolli mencionados anteriormente y así hablan de Juan y su hijo Juan Bautista, de su sobrino Esteban y de Francisco.

16 Véase una síntesis en López Torrijos, Rosa: Schede Bio-bibliografiche. Perolli, en La pittura in Liguria. Il Cinquecento, Génova 1999, pp. 403-405.

17 «La familia Peroli y otros italianos en Viso del Marqués (1575-1613)», B.M.I.C.A., LXXI, (1998), pp. 53-64. Sobre estos y otros datos de la actividad española de los Perolli trataremos en próximas publicaciones.

18 Pellegrino Antonio Orlandi Abecedario pittorico... Venezia MDCCLIII, p. 257, Ferdinando Fuga Supplemento alla serie dei trecento elogi e ritratti degli uomini i più illustri in pittura, scultura e architettura,1775.

19 P. Zani Enciclopedia metodica...delle Belle Arti, Parma 1819.

20 Por ejemplo, Mario Bressy, «Cesare Arbasia pittore saluzzese del cinquecento (1547-1607), L'Arte, 1961, p. 54; Catherine Wilkinson (que dice que permaneció en España hasta 1571), «Il Bergamasco e il Palazzo a Viso del Marques» en Galeazzo Alessi e l'architettura del cinquecento. Atti del convegno internazionale di studi. Genova 1974, pp. 626 y 628; Fiorella Caraceni (quien dice que acompañó al Bergamasco a España en 1567 y años después continúa trabajando en Génova para ir posteriormente a Piamonte), La committenza borghese e il manierismo a Genova en La Pittura a Genova e in Liguria dagli Inizi al Cinquecento. Genova ed. 1987, p. 291; Piero Boccardo (dice que Battista, Francesco y Stefano Perolli habían trabajado con el Bergamasco en Génova y le habían seguido a España en 1569), Andrea Doria e le Arti. Committenza e Mecenatismo a Genova, Roma 1989, p. 128; Mary Newcome (dice que Bergamasco vino con un equipo formado, entre otros, por el pintor cremonés Battista Perolli) Fresquistas genoveses en El Escorial, en Los frescos italianos de El Escorial, Madrid 1993 pp. 25-51, todo ello sin ninguna justificación o razonamiento.
} 
no), hijo de Esteban («filius quondam Stephani»). Generalmente se le nombra como pintor, aunque en 1564 aparece como «pictor y sculptor» en una ocasión y en 1566 se especifica, una sola vez, «pictor nunc Janue residens», tal vez precisión exclusiva de un notario. A partir de 1566 se le suele anteponer el título de magister y en 1574 se le llama ya arquitecto.

Así pues, sabemos que era de Crema y que era hijo de Esteban, puesto que así lo hace constar en la documentación,. No obstante el apellido Perolis o Perola no aparece, que sepamos, en repertorios, diccionarios, estudios o documentación sobre arte en Crema y su territorio ${ }^{21}$, así como tampoco en Génova o Liguria.

Sí aparece en Crema un «Domini Nicolai de Priolis», podestá y capitano del distrito de Crema, quien, junto a otros representantes de la Comunidad, contrata en 1490 con Giovanni Battaggio la construcción de Santa M. ${ }^{a}$ della Croce ${ }^{22}$.

También sabemos que en Palermo, en 1528, el cónsul de los genoveses se llamaba Giacomo Perollo ${ }^{23}$ y para rastrear un poco el origen de nuestro pintor tal vez pudiera servirnos la pista dada por un documento del Archivo de Estado de Génova, de 1568, en el que un Jacobus Perola - sin nada que ver con nuestro pintor - revoca un poder y hace constar que es hijo de Juan de Domodosera (Domodossola?), vallis Antigone. Es posible pues que el origen último de la familia no sea Crema, sino uno de los valles alpinos, lugar de procedencia común a tantos lombardos que trabajan en Génova ${ }^{24}$.

Al saberlo cremasco, se ha supuesto que Perolli llegaría a la ciudad formando parte del taller de Aurelio Busso, el pintor venido de Crema y de cuyo trabajo en Génova se conserva parte de la pintura realizada en la fachada del palacio Grimaldi (Meridiana), donde más tarde, como veremos, están documentados dos posibles discípulos suyos: Bergamasco y Perolli. El primero de ellos, como se recordará, tradicionalmente citado como introducido en Génova por Busso ${ }^{25}$.

Como iremos viendo, entre Perolli y Bergamasco existió siempre una estrecha relación, tanto profesional como personal, que se suponía iniciada en Génova, pero que a la luz de nuevos documentos sobre Castello es seguro que provenía ya de los años juveniles en Crema.

A este respecto son importantes las aportaciones de Marubbi en 1986. De acuerdo con sus investigaciones, Juan Bautista Castello siempre llamado el Bergamasco, no nació realmente en Bérgamo sino en Crema, pero fue llamado bergamasco por ser éste el origen de su familia.

\footnotetext{
21 Agradecemos mucho la ayuda prestada por la Doctora Licia Carubelli a este respecto. La bibliografía consultada sobre arte en Crema ha sido numerosa, la más importante se irá citando más adelante. Una síntesis de la literatura artística sobre la pintura cremasca puede verse en: Parisio, Chiara: La letteratura artistica sui pittori di Lodi, Treviglio, Caravaggio e Crema, en Pittura tra Adda e Serio. Lodi, Reviglio, Caravaggio, Crema, [A cura di Mina Gregori] Milano 1987, pp. 311318 .

${ }^{22}$ Giordano, Luisa, L'architettura en S.Maria della Croce a Crema, Cinisello B. (Milano), 1982 p. 34.

${ }^{23}$ La Barbera Bellia, Simonetta, La scultura della maniera in Sicilia, [Palermo], 1984, p. 14

${ }^{24}$ Precisamente de Domodossola proviene el apellido Galletus que llevan algunos canteros que trabajan en Génova por estas fechas también y que están relacionados con nuestro Perolli, como veremos más abajo (Dizionario di toponomastica, storia e significato dei nomi geografici italiani, Torino 1990).

${ }_{25}$ Soprani-Ratti ,Vite I, MDCCLXXVIII, p. 402. Busso, especializado en fresco y sobre todo en pintura de fachadas había comenzado con Polidoro da Caravaggio en Roma, pintando después en Crema, Génova, Venecia, Cremona y Milán. Entre sus obras conservadas en Crema destaca la decoración del palacio Zurla-De Poli (Zuchelli, Giorgio: La villa di caccia Zurla De-poli Cervi, en Le ville storiche del Cremasco, Crema 1998, pp. 69-90). Según cuenta Soprani (Vite, ob. cit. I, pp. 394-395) y recoge la bibliografía posterior, en Génova pintó el palacio Cattanei en la plaza de San Pancracio (perdido), y después fue llamado por Battista Grimaldi para trabajar en su palacio próximo a San Francisco, donde aun pueden verse huellas de decoración arquitectónica y algunos de los Trabajos de Hércules allí representados. Noticias más amplias da Giambattista Biffi, Memorie per servire alla storia degli artisti cremonesi, Edizione critica a cura di Luisa Bandera Gregori. Cremona, 1989 (Annali della Biblioteca Statale e Libreria Civica di Cremona, 1988, XXXIX/2 pp. 98-101). Para actualización de su biografía y relaciones con Giovanni Castello y los pintores cremascos véase: Caraceni ob. cit. p. 283 , Mario Marubbi Vincenzo Civerchio. Contributto alla cultura figurativa cremasca nel primo Ciquecento Milano $1986 \mathrm{p}$ 58ss. y Bora, Giulio. La cultura figurativa del Cinquecento a Crema e la decorazione a S.Maria della Croce en La Basilica di S.Maria della Croce a Crema, Milano 1990, pp. 91-145.
} 
Su abuelo, Giorgio de Castello «de terra Gandini» (recuérdese que a Castello se le consideraba nacido en Gandino) firmó en Crema, en 1520, contrato de aprendizaje en nombre de su hijo, Giovan Maria Castello, con el pintor Vincenzo Civerchio. En 1524 Giovan Maria casó con Ludovica, sobrina del pintor, compromotiéndose a vivir en su casa. Del matrimonio nacieron dos hijos, Giorgio y Giovanni Battista, ambos nombrados herederos universales de Civerchio en 1544, cuando ya había muerto su padre. Así pues el llamado Bergamasco nació realmente en Crema hacia 1526 o después (probablemente su hermano era mayor, ya que recibió el nombre del abuelo y se le cita siempre primero). Su formación se realizó con su padre, pero fundamentalmente con Civerchio y debió destacar prontamente en el arte, puesto que en un codicilo, extendido cuatro días después del testamento, Civerchio le deja expresamente a él la mitad de sus dibujos, las piedras de moler colores y todos los instrumentos «de pintar y grabar» ${ }^{26}$.

Esto hace que Castello sea mucho más joven de lo que se pensaba anteriormente (se suponía nacido hacia 1500), que conozcamos más precisamente su formación, que su llegada a Génova tuviese lugar probablemente después de 1544 y que el conocimiento de Busso se hubiese establecido ya en Crema ${ }^{27}$.

Se puede suponer igualmente que Perolli fuese de la misma o parecida edad que Bergamasco y que tuviese una formación similar. Tal vez coincidieran en Crema en el taller de Civerchio - aunque no haya ningún tipo de testimonio por el momento ${ }^{28}$ - y llegaran a Génova formando parte del equipo de Busso. Esta antigua amistad explicaría la temprana relación de Perolli y Castello, documentada en Génova, la participación de ambos en numerosas obras, el que se avalasen mutuamente en préstamos y contratos y el que pronto formasen sociedad mancomunadamente.

Bautista Perolli aparece inscrito en el Arte Dipintori et Indoratori poco después de Castello. Figura como Baptista de Perola y hace el n. ${ }^{\circ} 111$ de la relación, detrás de Baptista de Castello bergamasco, Valerius de Corte y Dominicus de Passano; posteriormente, detrás de Bernardo Castello y Aurelio Calvo, aparece Stefanus de Crema ${ }^{29}$.

Precisamente esta inscripción posterior a Bergamasco y los datos conocidos de su actividad primera en Génova, nos inclinan a pensar que Perolli debió llegar a la ciudad, no acompañando a Busso a mitad de los años 40, como se ha pensado hasta ahora, sino acompañando a

\footnotetext{
${ }^{26}$ Mario Marubbi, ob. cit. Milano 1986, p. 50ss, 67-ss doc. 26, p. 170, 33, 34, 35 pp. 173-175, 75, 76 pp. 191-192). Buen testimonio del valor que tenían los dibujos en los talleres de pintura nos da el hecho de que los de Civerchio fueron ya incluidos en el contrato de matrimonio entre su sobrina y el padre de J.B.Castello en 1524. Civerchio promete dejar a su muerte sus dibujos a Giovanni Maria si éste mantiene todo lo estipulado en el contrato y si no, podrá recibir una copia de ellos (p. 174). Dado que Giovanni M. murió antes que Civerchio éste los dejó a J.B. Castello y a Giovanni Maria de Flora por mitad, sin duda sus mejores discípulos.

${ }^{27}$ Sobre este tema véase, además de Marubbi ob. cit., Bora, ob. cit., pp. 91-145, especialmente pp. 105-113 y L.M. [Lorandi Marco], La decorazione tra Manierismo e Barocco: 1550-1650 en Pittura a Bergamo dal Romanico al Neoclassicismo a cura di Mina Gregori. Milano 1991, pp. 30-34. En el palacio Zurla-De Poli, de Crema, ya citado, se conserva una sala con pinturas al fresco de Aurelio Busso y otra con el Banquete de los dioses, anteriormente atribuido a él y después a Bergamasco (Bora, ob. cit., pp. 110-113 y Zuchelli ob. cit. pp. 76-79). Estas pinturas se consideran hechas entre 1546 y 1550, según los autores, es decir, después de terminado el trabajo genovés de Busso.

${ }_{28}$ Marubbi, ob. cit. no dice nada al respecto. Francesco Frangi (Pittura a Crema, en Pittura tra Adda e Serio. Lodi, Treviglio, Caravaggio, Crema, Milano 1987, pp. 243-318) habla de la dificultad de conocer los talleres cremascos y de como no hay personalidades en la ciudad que puedan competir con Civerchio en su tiempo .

${ }_{29}$ Capitula Artium. Archivio del Comune di Genova, Magistrato dei Padri del Comune. Manuscrito 430, II, p. 198r (a lápiz). Es un manuscrito de los siglos XVI-XVII, la relación aparece en una hoja posterior a otra con datos de 1550 . En otro manuscrito del siglo xvIII, conservado en la Biblioteca Berio de Génova, que copia igualmente la «Matricola Artis Pictorie et Scutarie» de Génova, Baptista de Perolla hace el número 102, situado igualmente poco detrás de Castello ( ${ }^{\circ}$ 95) y bastante antes de Stephanus de Crema ( $\left.n^{\circ} 136\right)$ (Véase Giovanna Rosso del Brenna, «Arte della pittura nella città di Genova» Trascrizione a cura di... La berio, 1976, XVI, n.1, pp. 27-28).

No sabemos si el Stephanus de Crema pintor, citado, tiene alguna relación familiar con Perolli, como podría suponerse por el origen común y la insistencia del nombre Stephanus - que llevaba su padre - en la etapa española de la familia Perolli.
} 
Castello a finales de esa década o comienzos de la siguiente, después de las nuevas actividades del Bergamasco en su ciudad natal ${ }^{30}$.

Nada sabemos por ahora de sus primeras obras en la ciudad. Su papel debió ser secundario y así lo demuestra también la sociedad que estableció en 1554 para realizar trabajos relacionados con prendas de lujo.

En efecto, el primer documento notarial conocido hasta ahora, relativo a nuestro pintor, se extiende el 22 de noviembre de 1554 y corresponde a la constitución de una sociedad «de arte designatoris et recamatoris» entre el maestro Nicolás de Carpis, pintor, y Batista de Perolis, pintor, por un período de diez años. El trabajo se ha de realizar en el taller de Nicolás en el barrio (contrada) de Mari, ambos pintores irían a medias en los ingresos producidos por el trabajo en el taller o fuera de él, así como en los gastos. En el taller cada uno tendría un aprendiz cuyo mantenimiento debería atender fuera de la sociedad constituida. Juan Bautista Castello, el Bergamasco, participa también en la sociedad, en lo que se refiere al trabajo de las pieles aplicadas a los terciopelos, correspondiéndole la mitad de las ganancias obtenidas por este concepto y durante el tiempo que él desee ${ }^{31}$. Como testigo se cita a Nicolas de Passano, miembro de una familia que tendrá larga relación con Perolli ${ }^{32}$.

Durante el período de diez años que cubre este compromiso son muy pocos los datos que poseemos sobre las actividades artísticas de Perolli, aunque sabemos que fue elegido Cónsul del Arte de la Pintura en 1560 junto a Agustín de Plazius ${ }^{33}$. Precisamente por su relación probada con Castello se le ha atribuido recientemente una Adoración de los Reyes ${ }^{34}$ (fig. 1), que, de ser suya, constituiría la única tela conocida hasta ahora de su actividad en Génova. La atribución se basa en la suposición de que Perolli terminó una pintura encargada al Bergamasco para la capilla de Antonio María Grimaldi, en la iglesia de San Francisco en Castelleto. El contrato es de 1562 y entre las obras comprometidas hay un cuadro de la Epifanía ${ }^{35}$. La obra se encuentra actualmente en la oficina del Ispetorato Compartimentale delle Imposte Dirette y proviene de la iglesia de San Salvador. Alizeri la vio en esa iglesia en 1846, proveniente de los

\footnotetext{
${ }^{30}$ Véase nota 27 con la atribución a J.B. Castello del techo con el Banquete de los dioses en el palacio Zurla- De Poli de Crema. La participación del Bergamasco en la pintura de este palacio no está documentada, pero es muy tentador, aunque totalmente gratuito, pensar que Perolli pudo coincidir también allí. En el palacio existe otra sala con Historias de Naam el Sirio, atribuida a un discípulo del Busso, en torno a los años 50 y que muestra «un pennello più di un decoratore che di un pittore» (Zuchelli, ob. cit., p. 86). Este pintor inexperto podría ser Perolli que siempre ejerció especialmente como pintor decorador. Las historias de Naam se representan dentro de cartelas sostenidas por figuras femeninas y separadas por putti que sostienen vasos. Un tipo similar de putti sosteniendo vasos se utiliza en la decoración de la sala de Troya de la villa Grimaldi de Sanpierdarena (Génova), para enmarcar los recuadros historiados. (Véase más abajo, obras de la villa Grimaldi).

${ }^{31}$ Las relaciones de pintores y bordadores eran estrechas y precisamente Bergamasco, siendo Cónsul del Arte de la Pintura, dos años antes de constituirse la sociedad, había denunciado a los bordadores (ricamatori) porque no querían adecuarse a los capítulos del arte de pintores. (Federigo Alizeri, Notizie dei Professori del disegno in Liguria dalle origini al secolo XVI. II, Genova 1873, p. 474, y Giovanna Rosso del Brenna Giovanni Battista Castello en I pittori bergamaschi dal XIII al XIX secolo. II, Il Cinquecento, Bergamo 1976, pp. 384-385.

32 A.S.G. Stefano Tubino sc. 278, f. 3. El documento fue publicado y transcrito por Alizeri ob. cit. II, p. 474.

33 Archivio del Comune di Genova. Magistrato dei Padri del Comune, filza 24 doc. 74 del 26-9-1560. Agradezco mucho a la profesora Elena Parma la notificación de la existencia de este documento. Lauro Magnani dio noticia del cargo en $L u c a$ Cambiaso da Genova all'Escorial Genova, 1995, p. 189, aunque sin hacer referencia a la fuente. Agustín Plazius (Plaxius o Piaggio) aparece inscrito en el Arte de la Pintura próximo a Perolli. Es hijo del pintor Teramo Piaggio y hasta muy recientemente no se sabía nada de su actividad pictórica. Sobre ésta y sus relaciones con otros pintores véase: López Torrijos, Rosa, «Nuevos documentos sobre pintores genoveses (Piaggio, Cambiaso y Semino)», Studi di storia delle arti, 1999 (en prensa).

${ }^{34}$ La atribución en: Magnani, Lauro, Luca Cambiaso da Genova all'Escorial Genova 1995, p. 189. Mi agradecimiento al profesor Boggero, quien me comunicó con bastante antelación el hallazgo de la obra y su atribución y me facilitó la fotografía que aquí se publica.

${ }^{35}$ El conjunto comprendía la pintura al fresco de la bóveda y tres cuadros al óleo descritos por Soprani (Soprani, Raffaello y Ratti, Carlo Giuseppe. Vite de'pittori, scultori ed architetti genovesi, [Genova 1768] ed. Bologna 1969, I, p. 404. El contrato fue publicado por Ennio Poleggi (Strada Nuova, una lottizzazione del Cinquecento a Genova, Genova [1968] ed. 1972, p. 499.
} 


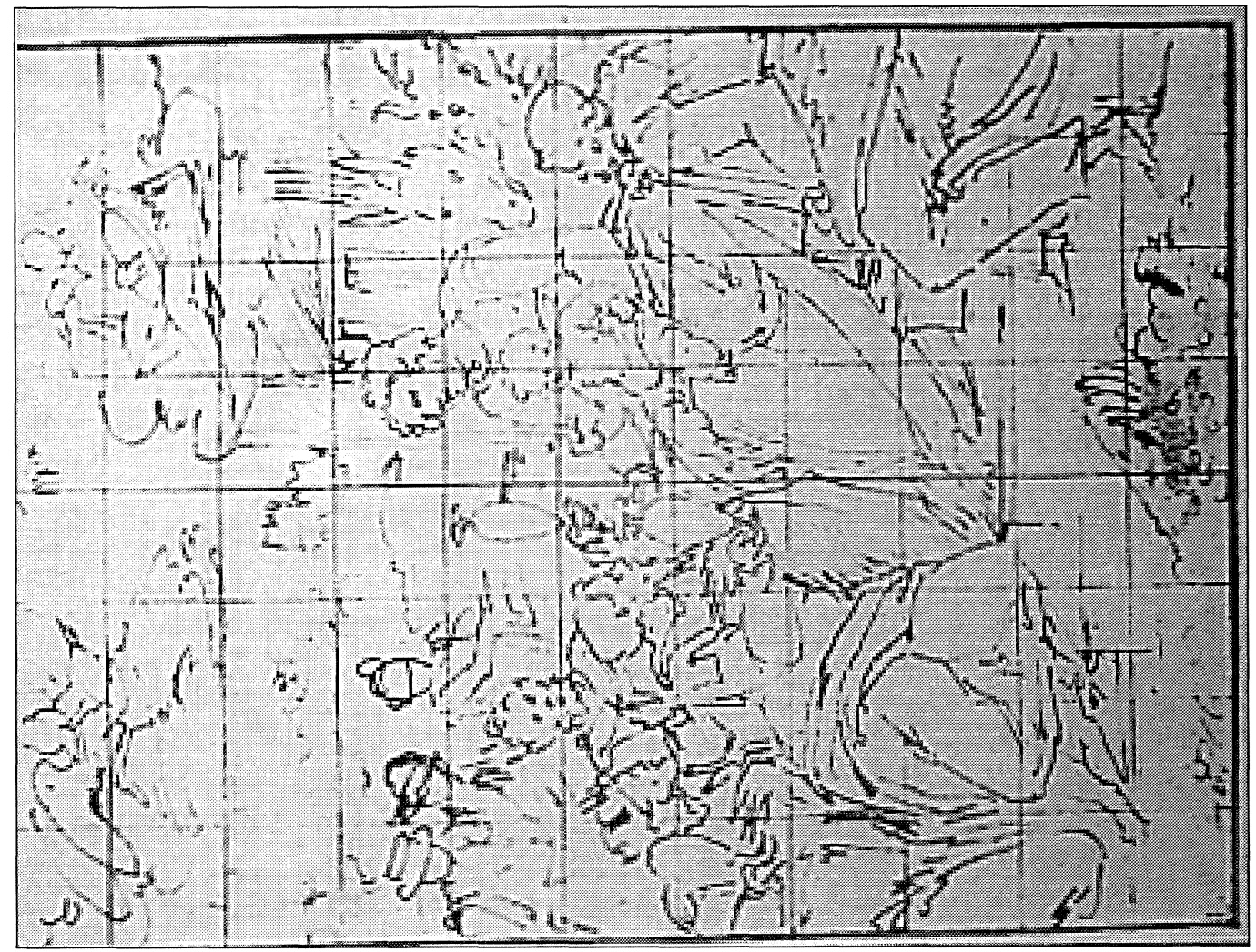

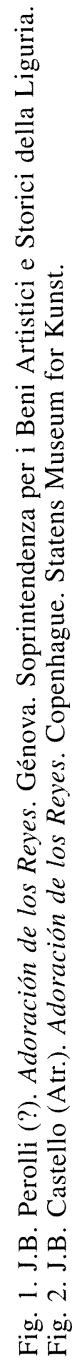

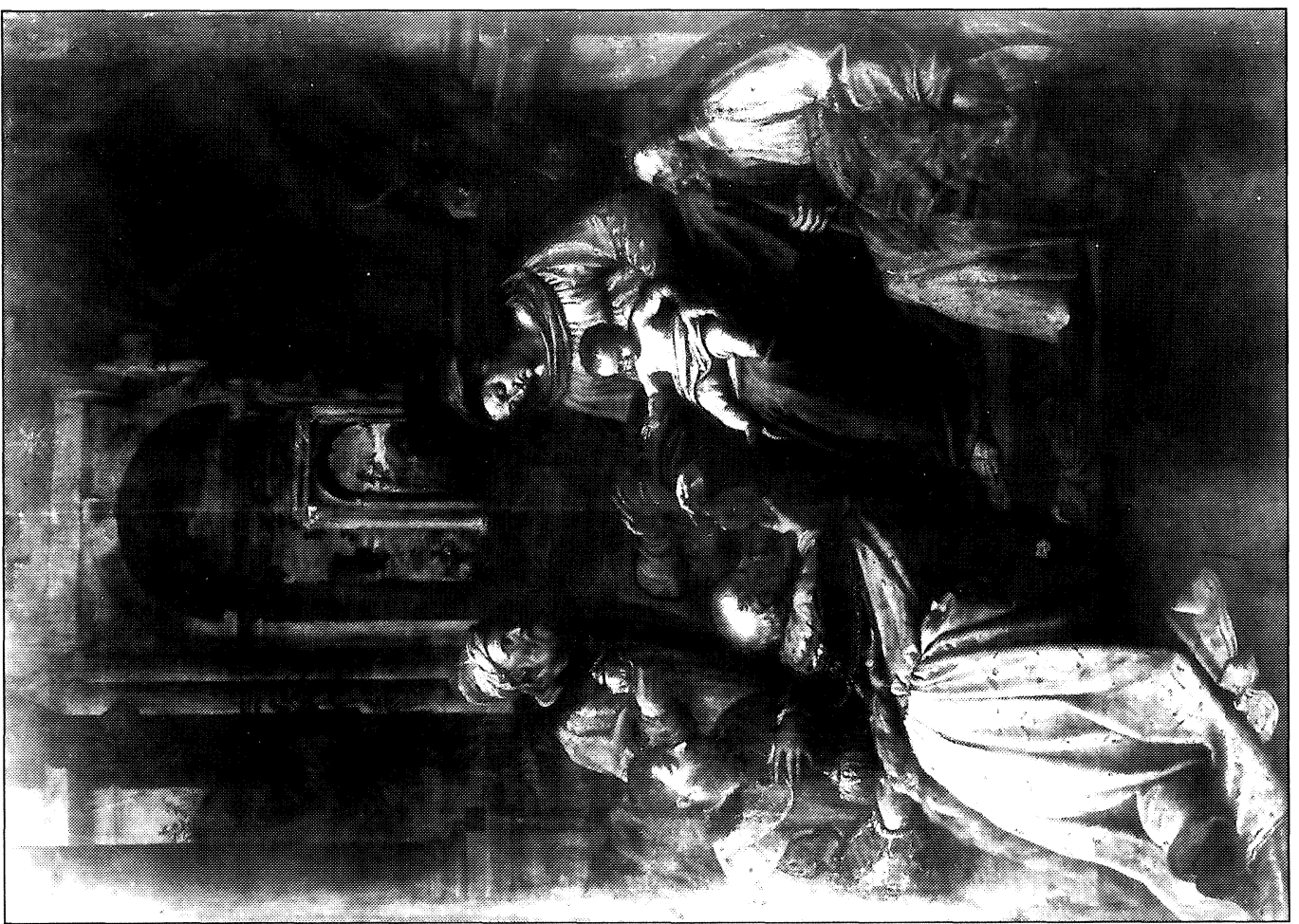


conventos suprimidos y la atribuyó al Bergamasco, identificándola con el cuadro del mismo tema pintado por él en la iglesia de San Francisco, una de las suprimidas ${ }^{36}$. En 1875, el mismo Alizeri indicó que debía provenir de San Francisco y que, si así fuera, sería, según la documentación, de Battista Perolli de Crema ${ }^{37}$. Además, la composición coincide en gran parte con un dibujo del Statens Museum fur Kunst de Copenhague, atribuido recientemente al Bergamas$\operatorname{co}^{38}$ (fig. 2), lo que vendría a apoyar la suposición de Alizeri. Haría falta no obstante confirmar que la pintura de San Salvador procede de San Francisco.

La atribución es difícil de confirmar estilísticamente ya que no puede compararse con otras obras genovesas y el estilo es diferente a los frescos que Perolli realizó en España. No obstante, estudiado el originąl, podría decirse, en nuestra opinión, que en el lienzo están más patentes las relaciones con la pintura lombarda (cremonesa) que con Bergamasco y que, vista la calidad de la obra y su fecha, se explicaría la prioridad que Perolli tuvo siempre como pintor.

La documentación encontrada hasta ahora sobre Perolli en este decenio es muy escasa y se refiere a actividades económicas cuyo contenido concreto ignoramos, pero que seguramente indican una modesta actividad artística por parte de Perolli y una necesidad de completar unos ingresos no muy cuantiosos.

Así por ejemplo, el 10 de marzo de 1563 Bautista Perolli recibe de Benedicto de Auria ciento treinta y seis libras genovesas como pago de la suma contenida en una letra de cambio de dicho Benedicto, del día 14-12-1562, y el día 6 de septiembre de 1563 vuelve a recibir de la misma persona y por la misma causa doscientas doce libras genovesas ${ }^{39}$.

En 1564 otro documento testifica que Perolli mantiene relaciones comerciales con paisanos de Crema que le envían mercancías para vender en Génova y a cuyos pagos podrían corresponder letras como las citadas anteriormente ${ }^{40}$. Así, el 18 de enero de ese año Baptista de Perollis «pintor en Génova» manifiesta su voluntad de pagar a Joanni Antonio Montanario quondam Jacobi ${ }^{41}$, también cremasco, 496 libras en moneda de Génova por mercancías enviadas por Montanario desde Crema y que fueron vendidas por Perolli. Por éste intercede y es fideiusuario «Joannes Baptista de Castello quondam Joannis Marie de Bergamo», habitante en Génova, a quien Perolli a su vez, promete liberar. Los testigos son también cremascos, entre ellos un Joseph Montanarius, Gregorii. El pago total se efectúa realmente el 10 noviembre ${ }^{42}$.

\footnotetext{
${ }^{36}$ Guida artistica per la città di Genova, Genova, I, MDCCCXLVI, p. 285.

37 [Iglesia parroquial de San Salvador] «l'ottimo [quadro] è quel dei Magi sull'altare secondo a sinistra; non nato per questa chiesa, ma proveniente (s'io non erro) da S.Francesco de'Conventuali, là dove gli atti mel dicono di Battista Perolli da Crema; di stile sifatto, che il cambieresti pel dilicato del Bergamasco» (Guida illustrativa del cittadino e del forastiero per la città di Genova e sue adiacente, Genova 1875, p. 83).

38 Newcome, Mary, «Drawings by Il Bergamasco for his Paintings in the Grimaldi Chapel» Master Drawings 1995, pp. 414-417.

39 A.S.G. Not. Giacomo Villamarino sc.190, f. 15, doc.97 y 359.

${ }^{40}$ Como es sabido, Crema, que pertenecía a Venecia desde 1454 , tiene en estos años una gran actividad económica y un intenso intercambio con Génova en el comercio de hilados y telas de lino y seda, fundamentalmente, además de su habitual y rica producción agrícola. G. Bora (ob. cit.,1990, p. 105) indica que en Crema existían más de 800 telares y unas quince fábricas de terciopelo y que en Génova existía una sólida colonia de artesanos cremascos. Para una visión histórica de conjunto de Crema en estos años puede verse: Chittolini, Giorgio: Una regione di confine: lineamenti storici, en Pittura tra Adda e Serio. Lodi, Treviglio, Caravaggio, Crema, Milano 1987, pp. 325-331.

${ }^{41}$ Giovanni Antonio Montanario se llama también el arquitecto que terminó, en 1500, uno de los edificios más importantes de la Crema, la iglesia de S. Maria della Croce. Un Vincentiun quondam Antonii de Montanariis aparece como testigo en el testamento del pintor Civerchio, hecho en Crema en 1544 (Marubbi, ob. cit., p. 192), lo que indica las relaciones continuas entre estas familias cremascas.

42 A.S.G. Antonio Tinello sc.259, f. 6. El documento dice así:

1564, 18 januarii.Promissio pro Jo. Antonio Montanario.

+MDLXIIII die martis, in terciis, in Bancis ad banchum Jo. infrascripti, indictione sexta. Baptista de Perollis de Crema pitor in Janua, confessus, sponte, etc. dare et solvere Joanni Antonio Montanario etiam de Crema, quondam Jacobi, presenti, etc. sive persone legiptime, libras quatuorcentumnonagintasex monete Janue et sunt pro processu cantariorum ducentorum mercium per ipsum Joannem Antonium ex dicta civitate Creme missarum dicto BAPTISTE, pro ipsis vendendis et quas ipse
} 
A partir de esta fecha - en que por cierto vence el compromiso con Nicolás de Carpiconocemos las primeras obras documentadas de Perolli como escultor. Se hace llamar así en los contratos y éstos indican además que ya poseía taller propio.

Esta década de los sesenta es de gran actividad artística en Génova. Además de la construcción de Santa María in Carignano por Alessi, maestros genoveses que trabajan con él (Cantone, Spazio, Ponzello) construyen buena parte de los palacios de la Via Nuova (Strada Nuova), el ambicioso proyecto iniciado en los cincuenta. Todo esto supone igualmente una gran demanda de trabajos relacionados con la decoración interna y externa de los palacios y por tanto un gran movimiento de artistas y artesanos comprometidos en labores de pintura, escultura, revestimentos, pavimentos, ebanistería, etc. etc., además de la continua actividad exportadora, en la que España tiene un peso específico.

Génova pues atrae a numerosos forasteros que engrosan el número siempre abundante de sus colonias respectivas, entre las cuales resalta por su importancia y antigüedad, la de los lombardos (de la cual se separaron los cremascos al pasar a depender de Venecia). Todos ellos, cuando es necesario, amplian el llamamiento a familiares y amigos de sus lugares de origen y atienden así la creciente demanda, especialmente de canteros, marmolistas y escultores, pero también en ocasiones de pintores.

A finales de los años cincuenta comienza la etapa de mayor actividad de J.B.Castello, el socio de Perolli y Carpis en 1554. Su nombre aparece asociado a las familias más relevantes de Génova, comenzando por los Pallavicini y continuando con los Grimaldi, Giustiniani, Doria, Imperiale, Spinola, Lomellini, Lercari, y a obras de primera importancia en villas suburbanas, palacios dentro y fuera de Strada Nuova, iglesias, capillas, etc. Bergamasco actúa no solamente como pintor sino también como arquitecto, y fundamentalmente como director del proyecto decorativo del edificio. Su nombre aparece relacionado prontamente con Cambiaso y frecuentemente proyecta, dibuja, contrata y juzga a y para los Lurago, Carlone, Cantone, Ponzello, Forlano, Da Nove, Orsolino, Carabio, etc. ${ }^{43}$. En este contexto es significativa la presencia de Bautista Perolli, quien pronto aparece como la persona más cercana al Bergamasco, terminando sus trabajos incompletos, proporcionando esculturas o elementos decorativos en las obras de Castello, ofreciendo garantía por sus préstamos, etc., así hasta la partida del Bergamasco a España, en que Perolli, que permanece en Génova, hereda parte de las obras de Castello y le sustituye en algunos proyectos.

En 1562 Bergamasco comienza a trabajar para los Grimaldi, contratando con Antonio María la decoración de su capilla en San Francisco, una de cuyas telas termina Battista Perolli, según Alizeri (la Adoración de los Reyes, anteriormente vista).

En 1563 contrata con Bautista Grimaldi frescos, estucos y óleos en el ábside de la iglesia de la Anunziata de Portoria de Génova y desde 1565 interviene en las obras de su palacio en San Francisco en Castelletto y de su villa en Sampierdarena (Fortezza); en ambos, como veremos, trabajará Perolli.

Baptista vendidit et hoc comprehensis partitis seu deductis aliis partitis ipsi Jo. Antonio solutis ad complementum precii dictarum mercium ut sponte fatentur... Et pro eo intercessit et fideiussit, Joannes Baptista de Castello, quondam joannis Marie de Bergamo, habitator in Janue... Quem Joannem Baptistam ipse Baptista promissit eum relevare, etc.Testes Franciscus Pandinus de Crema quondam Aloixii et Joseph Montanarius, Gregorii, vocati.

+MDLXIIII die veneris X decembris in Bancis ad banchum.

Supradictus Jo. Antonius Montanarius sponte, fatetur habuisse et recepisse a Baptista de Perollis, presente et aceptante, supradictas libras quatuorcentum nonaginta sex januinorum de numerato et sunt ad quas tenebatur virtute dicti instrumenti. Renuncians..

43 Sobre Bergamasco, el estudio fundamental de conjunto sigue siendo el de Rosso del Brenna, Giovanna,Giovanni Battista Castello (ob. cit.,1976, pp. 377-487). Ella misma hizo la voz correspondiente en el Dizionario biografico degli italiani 1978, vol. 21. También el de Caraceni Poleggi, Fiorella, La committenza borghese e il manierismo a Genova en La Pittura a Genova e in Liguria dagli Inizi al Cinquecento. Genova, última edición puesta al día 1987, pp. 223-301. 
Pero antes de ésto tenemos la primera noticia de una colaboración entre Castello y Perolli relacionada con España.

La noticia proviene de Esteban de Garibay, el célebre historiador español, cronista de $\mathrm{Fe}$ lipe II, quien incluye en su genealogía del marqués de Santa Cruz, un breve apunte sobre «la hermosa casa fabricada en El Viso», diciendo que se comenzó el 15 de Noviembre de 1564 y que fueron sus maestros Juan Bautista Bergamasco, arquitecto y Juan Bautista Olamasquin arquitecto y escultor, ambos italianos como el resto de los que participan en la obra. Esta noticia, incluida en un manuscrito de Garibay, que conocemos solo por copias posteriores, ha dado por mucho tiempo la paternidad del palacio del Viso del Marqués a Juan Bautista Castello, dejando en el olvido al desconocido Olamasquin, del que nunca más se supo, ni en Italia ni en España.

Como hemos tratado en otro lugar ${ }^{44}$, el Olamasquin de Garibay es una mala lectura (suya o de su comunicante) de Cremaschino (españolizando además la terminación) y corresponde pues a nuestro Juan Bautista Perolli de Crema. Esto probaría que el dato se tomó de un documento - perdido por ahora - relativo a obras en el palacio de los Bazán, aunque no ciertamente al comienzo de su construcción, que fue anterior, como se ha podido demostrar con documentación española ${ }^{45}$.

Aunque es difícil de saber, no conociendo el documento original, resulta extraño que en él apareciese Perolli como arquitecto, categoría que solo al final tuvo en Génova y hay que suponer que figurase junto a Castello en un trabajo de arquitectura (probablemente una traza para alguna parte del palacio, ¿la escalera?), tal vez con intención de implicarle en futuros compromisos de piezas o personal necesarios para el palacio y relacionados con la escultura ${ }^{46} \mathrm{o}$, más bien, como resultado de una asociación entre ambos, al finalizar el compromiso de diez años con Nicolás de Carpi, lo que parece estar más de acuerdo con toda la documentación posterior.

El primer contrato genovés de Perolli, relacionado con la escultura, lleva fecha 15-12-1564. Se establece entre Baptista de Perolis «pictor et sculptor» y Battista Grimaldi quondam D. Jeronimi ${ }^{47}$, en él se compromete a hacer antes de ocho meses, seis bustos de mármol «de la calidad de los que tiene en su casa el noble Luca de Grimaldi» ${ }^{48}$, se entregarán en el taller de

${ }^{44}$ López Torrijos, Rosa, «Garibay y los arquitectos del palacio del Viso», Goya, (en prensa).

45 Todas las noticias y documentación están recogidas en López Torrijos, Rosa, Palazzo di Don Alvaro de Bazán, en La pittura genovese..., ob. cit., 1999, pp. 229-244.

${ }^{46}$ De hecho, dos años después, cuando se requirió personal para la construcción, quienes vinieron al Viso fueron Andrea Roderio de Carona, «arquitecto» y otros tres «antelami» lombardos (Poleggi, ob. cit., ed.1972, p. 513).

${ }^{47}$ Este Battista Grimaldi es hijo único de Girolamo q.Giorgio. Su padre era comerciante y banquero con grandes intereses en España y Portugal. Este, al parecer había residido en nuestro país y tenía el monopolio de los impuestos municipales de Córdoba y Granada. Murió en 1557 y no hay que confundirlo — como se ha hecho hasta muy recientemente-con el cardenal Girolamo Grimaldi padre de otro Giovan Battista, igualmente importante por sus encargos artísticos e igualmente vinculado a España, cuyo hijo Ansaldo, al servicio de Felipe II, fue nombrado marqués de Modugno. (Véase al respecto: Hobson, Anthony «La biblioteca di Giovanni Battista Grimaldi» Atti della Società Ligure di Storia Patria, 1980 N.S.XX (XCIV),II p. 108-119 y Melai, Roberto «Il palazzo di Girolamo Grimaldi a S. Francesco di Castelleto» en Studi in memoria di Teofilo Ossian De Negri, I, 1986, pp. 76-80). Sobre el segundo G.B. Grimaldi puede verse también: López Torrijos, Rosa, «Imágenes, textos y personajes en torno a la propuesta de una ciudad ideal presentada a España en el siglo XVI», A.D.H.T.A. XI (1999), pp. 93-99.

${ }^{48}$ Este Luca es hermano del otro Battista Grimaldi (véase nota anterior), ambos hijos de Girolamo Grimaldi q.Benedicti, aunque generalmente aparecen citados como hijos de Girolamo cardenal, ya que el papa Clemente VII hizo cardenal a su padre cuando quedó viudo. Girolamo era sobrino de Ansaldo Grimaldi, llamado el rey del alumbre, una de las mayores fortunas de Génova, que al morir dejó en manos de Girolamo (Melai ob. cit.). Gómez Suárez de Figueroa, embajador de España en Génova, dice en una carta a Francisco de los Cobos, que Ansaldo Grimaldi ha muerto el 30-9-1539 y que deja 500.000 escudos para que el cardenal su sobrino sea usufructuario en vida y después de muerto queden a los hijos del cardenal, añadiendo: «mucho me ha pesado porque aunque era miserable y avaro era buen servidor de S.Md.» (A.G.S. Estado 1372, fol. 63).

Luca vivía en el palacio de «familia» de los Grimaldi, lindando con el convento de S. Francisco y cuya fachada principal estaba situada en la misma subida de S. Francisco, justamente enfrente del palacio del otro Giovan Battista Grimaldi. 
Perolli ${ }^{49}$, por el precio de sesenta escudos de oro, de los cuales se le entregan veinte en el momento de la firma del contrato, veinte al terminar la mitad del trabajo y los otros veinte al finalizar el mismo. El escultor debe poner además el mármol «bello y bueno». En agosto del 1565 Perolli recibe de mano de Pascual hijo de Bautista Grimaldi otros veinte ducados «a buena cuenta» de lo contenido en el contrato anterior ${ }^{50}$.

Puesto que sabemos que en 1565 Bergamasco es quien dirige la decoración de las obras de J.B. Grimaldi en el palacio de San Francisco (construido en la década de los 40) y en la villa de Sampierdarena (iniciada en 1559) ${ }^{51}$, es de suponer que los bustos encargados a Perolli fuesen destinados a una de estas dos obras y tenemos aquí una base documental más del posible compromiso de Perolli con Bergamasco.

En 1565 también, se debió encargar a Perolli la estatua sedente de Bautista Grimaldi, destinada a la exposición de ciudadanos ejemplares del palacio de San Giorgio.

Como es sabido, el Ufficio di San Giorgio de Génova era su institución civil más prestigiosa, la cual estableció a finales del siglo XIV un sistema original de colaboración del capital privado en la amortización de la deuda pública (algo parecido a la actual compra de deuda pública con intereses), en el que se fueron implicando cada vez más ciudadanos y cuya organización ejemplar fue adquiriendo competencias cada vez más amplias, gestionando no solo la deuda pública sino también impuestos, monopolios, administración de colonias, etc. llegando a sustituir prácticamente al Comune en las actividades administrativas y financieras.

En 1451 el Comune cede al Ufficio di San Giorgio su palacio junto al mar - conocido después como Palacio de San Giorgio- y allí queda instalada su sede que, de hecho, representa igualmente al gobierno de la ciudad.

Desde 1466 se decide colocar en este palacio esculturas de ciudadanos ejemplares por ser benefactores financieros de la patria, una versión actualizada de las series de «hombres ilustres», creada por una comunidad que vive especialmente del comercio y de la banca. La serie se inauguró con Francisco Vivaldi, que había sido el primero en donar participaciones de préstamos al estado, con el fin de invertir los intereses en nuevas adquisiciones (el llamado «moltiplico»), hasta consegir un capital suficiente para emplearlo en obras públicas de utilidad común. A partir de entonces se regula la «expresión del agradecimiento» de la comunidad, de acuerdo con la donación efectuada (una lápida por donación de hasta 25.000 liras genovesas al Capitulo Comperae, un busto hasta 50.000, una estatua de pie entre 50.000 y 100.000 y una escultura sedente más allá de la última cantidad) ${ }^{52}$.

En este contexto surge el encargo oficial de una estatua sedente de Juan Bautista Grimaldi para el palacio de San Giorgio. La decisión se toma en $1565^{53}$, después del fideicomiso esta-

\footnotetext{
Luca, que es uno de los especuladores más importantes de Strada Nuova, habita el palacio en 1548. En el siglo xviII se construyó en su lugar el actual Palazzo Bianco (Ennio Poleggi Strada Nuova una lottizzazione del Cinquecento a Genova, Genova, ed. 1972, pp. 81-90).

${ }^{49}$ Obsérvese que ahora tiene taller propio, mientras en el contrato de 1554 se obligaba a trabajar en el de Nicolás de Carpi.

${ }_{50}$ A.S.G. Not. Leonardo Chiavari sc. 286 f. 8. Del documento dió noticia Caraceni (ob. cit., ed. 1987 p. 291 ) diciendo que los bustos eran para el palacio de San Francisco en Castelletto.

${ }^{51}$ Rosso, Giovanni, (ob. cit.),1976, pp. 381-82; documentos, p. 387.

${ }_{52}$ Parma Armani, Elena, Una svolta internazionale en La scultura a Genova e in Liguria. Dalle origini al cinquecento. I Genova, 1987, p. 311. Sobre la institución y el palacio de San Giorgio la bibliografía es abundante, un buen resumen de la institución y su manifestación artística puede verse en Elena Parma Armani, Il ritratto civile di commitenza pubblica a Genova nel Quattrocento. Statue di cittadini benemeriti in Palazzo San Giorgio en Il ritratto e la Memoria. Materiali 2 1993 pp. 135-172. También: Marengo, C., Manfroni, C.,Pessagno, G., Il Banco di San Giorgio, Genova 1911; Grosso, Orlando, Il palazzo San Giorgio, Genova 1968 y 1984; Rotondi Terminiello, Giovanna, Palazzo San Giorgio, Genova 1977 y Tagliaferro, Laura, Un secolo di marmo e di pietra: il Quattrocento, en La scultura a Genova... ob. cit., pp. $215-249$.

${ }_{53}$ Alizeri, ob. cit., 1875, p. 40.
} 
blecido por Grimaldi en $1559^{54}$ y la obra es realizada por Bautista de Crema, que cobra por ella 310 liras en 1567 según indica Alizeri ${ }^{55}$.

La escultura, como corresponde a la generosidad del retratado, es sedente, y actualmente preside la Sala delle Congreghe del palacio de San Giorgio (fig. 3). Siete años después se construyó una rica hornacina para alojar la escultura, realizada por Pier Maria de Novo de Lancio, actuando Perolli como árbitro del trabajo ${ }^{56}$. El hecho de que la obra se haya conservado nos permite apreciar el trabajo de Perolli como escultor. La obra, como es lógico dado el lugar y las circunstancia, da gran importancia a los elementos que resaltan la imagen pública y el recuerdo futuro del personaje ${ }^{57}$, la actitud elegida, la riqueza del sillón como verdadero trono, el traje de telas costosas y abundantes, todo subraya el carácter ostentoso con el que se quiere transmitir la riqueza y generosidad del retratado. Aunque la estatua sufrió pérdidas con el bombardeo del palacio en la última guerra mundial, podemos apreciar en las manos y el rostro el dominio de la técnica del mármol y la atención concentrada en estas partes, mientras en el cuerpo puede apreciarse la dificultad de encaje y proporción que observaremos en otras obras de Perolli.

Los compromisos del Bergamasco son cada vez mayores por estos años, lo que supone una dificultad en cumplir los plazos ${ }^{58}$ y por tanto una mayor participación de Perolli en sus obras.

Esto queda bien reflejado en el proceso de elaboración del altar de San Bartolomé. El 18 de febrero de 1566 Castello había contratado con el abad Tomás de Nigro un cuadro de altar para su capilla de San Bartolomé, en la iglesia de San Benigno de Capodifaro, según dibujo adjunto al documento, que conocemos (fig. 4$)^{59}$. El pintor recibe en ese momento 25 escudos de oro y otros 25 en abril del mismo año, pero en febrero de 1567 el comitente manifiesta que, aunque Castello hizo la mayor parte del altar, fue Bautista de Perolli quien lo terminó, y por ello éste declara que ha recibido el resto del importe total y que queda satisfecho en su nombre $y$ en el de Castello, ausente entonces ${ }^{60}$.

${ }^{54}$ Según Melai se trataba de 302.975 escudos a favor de numerosas obras públicas (el puerto, renovación y ampliación del palacio Ducale, completar el Lazareto della Foce, etc), religiosas (convento de S.Maria dell'Annunziata de Portoria) y de caridad (A.S.G.Cartulario originale delle colonne di S.Giorgio año 1559 P.N. apud Melai, ob. cit., pp. 74-75, n. 11.

55 (Ob. cit., 1847, II, parte I, p. 282). Indica que así aparece en los cartularios, aunque el documento nos es desconocido.

56 Alizeri da la noticia en 1875 (ob. cit., p. 40). De aquí provienen sin duda todas las referencias posteriores, que no dan cita documental precisa (Marengo, Manfroni y Pessagno, ob. cit. pp. 334 y 528; Grosso, ob. cit., 1968, p. 79). El contrato (A.S.G. Not. Gcmo. Ligalupo, sc.451 f. 5.) se hace entre Luca de Grimaldis y Petrus Maria de Novis de Lancio, escultor, el 20 de octubre de 1574 y en él se especifica que hará todos los ornamentos de mármol y de otros materiales que vayan bien para el hueco (fenestra) del aula magna de San Giorgio, en que debe ponerse la estatua de Bautista Grimaldi, según modelo que tiene el cancelario mayor del Ufficio di San Giorgio, Agustín Imperiale. Además colocará la estatua en la hornacina, entre dos columnas, no siendo de su cargo ni la estatua ni las columnas. Lo hará dentro del mes de noviembre y el precio será de 400 ó 425 libras, a juicio de Lucas Grimaldo y del maestro Bautista cremasco.

${ }^{57}$ En el pedestal de la hornacina hay una inscripción latina donde se da cuenta de las virtudes y donaciones de todo tipo del retratado.

${ }^{58}$ Recuérdese que en 1565 contrata como aprendiz a Francisco de Urbino, quien después lo acompañará a España (López Torrijos, Rosa, «Francisco de Urbino y Juan Bautista Castello antes de venir a España», Reales Sitios, 1997, pp. 14-18).

${ }^{59}$ El dibujo en efecto, se ha conservado dentro del legajo. El documento (A.S.G. Not. Leonardo Chiavari, sc. 283, f. 11) fue parcialmente transcrito por Rosso (Giovanni, ob. cit., 1976, pp. 387-388), y el dibujo publicado por Caraceni (ob. cit., ed. 1987, p. 247). En él se indican las medidas de la pintura y de todos los componentes del altar, que debía hacer igualmente Castello. En las partes no transcritas por Rosso se indica que el pintor debe poner la madera y materiales correspondientes, hacer en relieve dorado lo que está indicado como amarillo rojizo en el modelo y dejarlo todo a gusto de Francisco Pallavicino y Nicolás Imperiale.

${ }^{60}$ Todo ello en el legajo citado en la nota precedente. Por cierto, que en el legajo anterior (f. 10) hay otro documento, fechado dos meses antes, con el contrato de los mármoles para el cerramiento de la capilla. El documento, de fecha 6-121565, es el compromiso de los maestros Jacobo Carlone de Scaria y Juan Carlone, marmoleros de Rovi, del ducado de Milán, habitantes en Génova, con el mismo abad de Nigro, para realizar balaustres, pilastrillas, angelitos y cornisas para la capilla que el abad quiere construir en la iglesia de San Benigno y que deben estar terminados en el mes de abril siguiente. Todos los elementos deben ser iguales a los de la capilla de Benedicto Gentile en la misma iglesia, y el precio es de 20 sueldos de Génova por balaustre, 18 por palmo de cornisa y entre 19 y 20 libras de Génova por cada pilastrilla con su 
Tenemos pues aquí lo que podría ser un caso similar al de la Adoración de los Reyes citada anteriormente. Una pintura encargada al Bergamasco, con modelo suyo conocido y terminación final de Perolli. Desafortundamente la pintura se ha perdido, por lo que no podemos estudiar comparativamente ambos lienzos y sacar conclusiones ${ }^{61}$.

De 1566 es el primer documento conocido de la participación de J.B. Perolli en las obras de la villa de Battista Grimaldi en Sampierdarena.

La villa construida en Sampierdarena por Juan Bautista Grimaldi, nos vuelve a situar ante una colaboración de Perolli con Bergamasco, primero en tareas menores bajo la dirección de Castello y después sustituyéndole en la supervisión o dirección de la parte decorativa. El nuevo compromiso es para un cliente ya conocido anteriormente.

Juan Bautista Grimaldi, dueño del palacio urbano de la calle que sube a San Francisco, hace construir la villa fuera de la ciudad siguiendo la moda renacentista de «huida al campo». Es el lugar donde suele «vivir a lo rústico», según expresa uno de los documentos contemporáneos ${ }^{62}$. El edificio, conocido también como «Fortezza», estaba situado junto a la playa (en los documentos se suele especificar la entrega de materiales «en la playa de San Pietro de Arena») y fue edificado en terrenos heredados por Juan Bautista y ampliados con compras suyas de propiedades vecinas (Lomellino y Usodimare), constituyendo así una gran finca de ocio y de labor.

En ella residió Rubens cuando visitó Génova acompañando al duque de Mantua, en 1607. Entonces pertenecía a Julia, mujer de Pascual Grimaldi, hijo de Juan Bautista, y a su nieto va dedicado el libro del pintor sobre los palacios de Génova. La villa, incluida en la publicación de Rubens, recibe nueve ilustraciones, más que ningún otro edificio ${ }^{63}$ y gracias a ellas conocemos, no solo planta y secciones originales, sino partes perdidas del palacio como el baño y la decoración de sus fachadas, especialmente interesantes para nosotros.

La villa fue atribuida a Alessi por Vasari y mantuvo esta atribución hasta nuestro siglo. En 1925 Labò publicó su primer estudio y en él subrayó los elementos alessianos más característicos — presentes en Génova en la villa Giustiniani (Cambiaso) construida por Alessi en la década de los 40-, como la apariencia de cubo, la fachada dividida en tres partes con el cuerpo central rehundido y la planta, de claras referencias alessianas especialmente marcadas en las logias de ambos pisos. Pero también señaló elementos decorativos del repertorio del Bergamasco y dió a conocer abundante documentación sobre el palacio. En ella aparecen noticias de trabajos ya en 1561 (adquisición de materiales), la presencia de Bernardo Spazio como primer arquitecto de la obra en 1562 y 1563, la posterior de Cantone y Ponzello y la participación de Perolli junto a Bergamasco ${ }^{64}$.

angelito, debiendo quedar todo a gusto de Andrea Imperiale y recibiendo ambos en ese momento 20 escudos de oro a cuenta (A.S.G. Leonardo Chiavari sc.287 filza $10 n^{\circ} 24979$ ).

${ }^{61}$ El monasterio de San Benigno di Capodifaro fue fundado en 1121 por los benedictinos y tuvo siempre una vida difícil, en parte motivada por su situación geográfica clave para el dominio de la ciudad. La inseguridad del lugar hizo que los frailes lo abandonaran a principios del siglo XVI, volviendo a él en la segunda mitad del siglo, gracias a las restauraciones patrocinadas por Andrés Imperiale y Benedicto Gentile (obsérvese que el primero es el árbitro elegido para juzgar la obra de escultura encargada por el abad De Nigro y el segundo el propietario de la capilla que se ha de tomar como modelo para la misma obra). En 1850 se destruyó totalmente, pero antes se había despojado a la iglesia de cuadros y mármoles, entre los cuales estarían las obras que ahora nos interesan y cuyo paradero desconocemos. (Datos tomados de Colombo, Silvia,San Benigno di Capodifaro, en Medioevo demolito. Genova 1860-1940, Genova 1990 p. 57-70. En este estudio la autora da una hipotética planta de la iglesia, basada en datos de un documento de 1579 , en ella la capilla del abad De Nigro (San Bartolomé) es la tercera de la parte izquierda, justamente enfrente de la de Benedicto Gentile (San Benedicto).

${ }^{62}$ El 6-3-1563 Oberto de Glarea promete a Bautista de Grimaldis entregar 250 modios de cal en la playa de Sampierdarena, frente a la villa que tiene en ese mismo lugar «in qua dictus M.D. Baptista rusticare solet» (A.S.G. Not. Carosso, f. $3, \mathrm{n}^{\circ} 2052$ ).

${ }^{63}$ Labò, Mario, I palazzi di Genova di Pietro Paolo Rubens e altri scritti d'architettura, Genova, 1970, p. 63.

${ }^{64}$ Labò, Mario, «Studi di architettura genovese. La villa di Battista Grimaldi a Sampierdarena e il palazzo D'Oria in “Strada Nuova”», L'Arte (1925), pp. 271-280, ampliado en 1970 en el estudio citado en nota 63. 

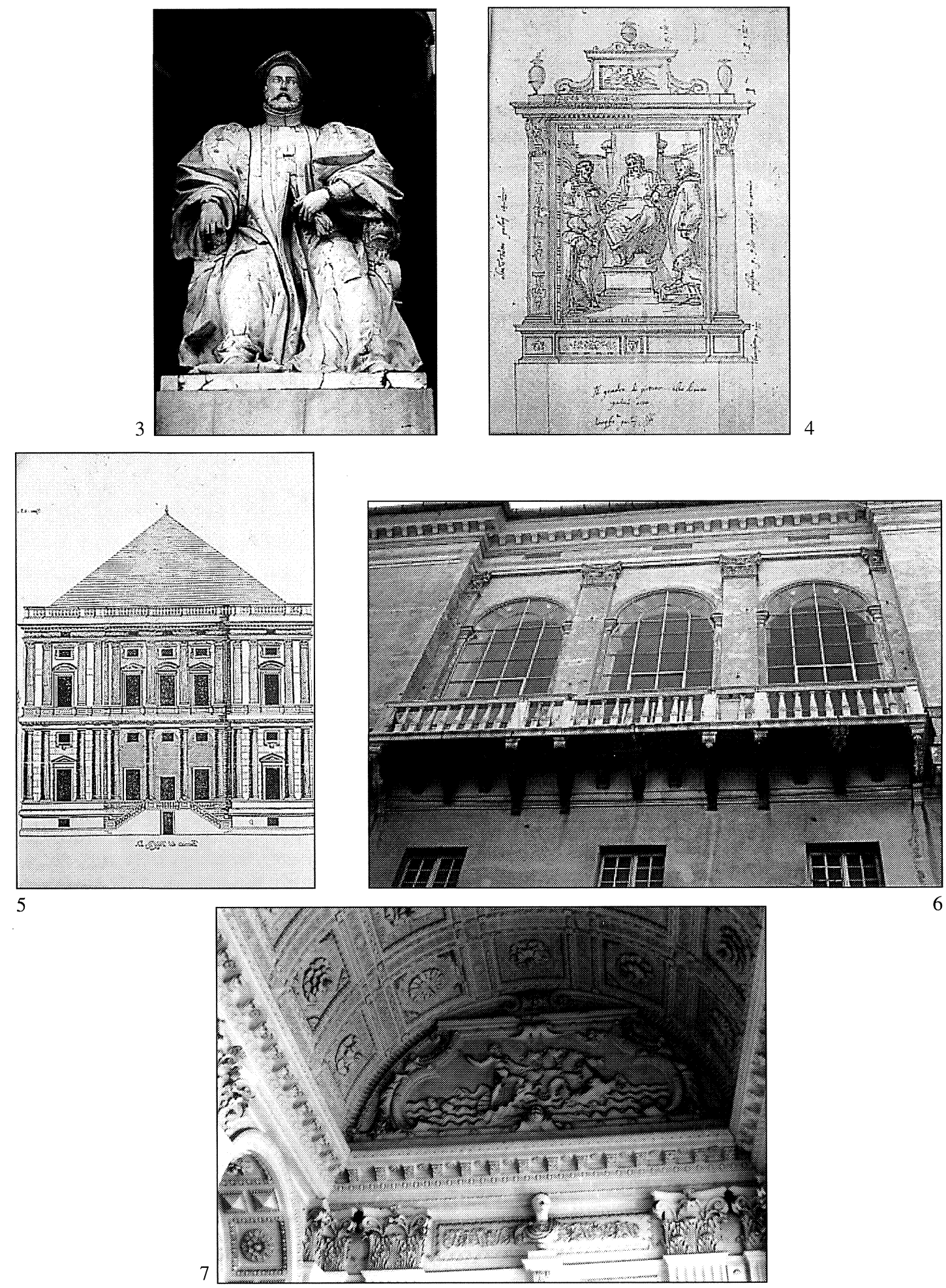

Fig. 3. J.B. Perolli. Juan Bautista Grimaldi. Génova. Palazzo di San Giorgio.

Fig. 4. J.B. Castello. Dibujo para el altar de San Bartolomé. Génova. Archivio di Stato.

Fig. 5. J.B. Perolli. Pintura de la fachada de Villa Grimaldi en Sampierdarena según el libro de Rubens.

Fig. 6. J.B. Perolli. Balcón de la villa Grimaldi (fachada norte). Génova, Sampierdarena.

Fig. 7. Carona y L. Cambiaso. Estucos de la logia de Villa Grimaldi. Génova, Sampierdarena. 
Más tarde, Poleggi, al estudiar los palacios de Strada Nuova y las personalidades de Bernardo Spazio, Bernardino Cantone y Juan Ponzello, analiza en profundidad sus formas y adscribe la obra a Spazio y tras su muerte a Ponzello ${ }^{65}$, al tiempo que añade nueva documentación.

A través de toda esta documentación, y de alguna otra encontrada por nosotros en la investigación sobre Perolli, podemos establecer las etapas de construcción, recordar la decoración perdida, conocer la participación del «cremaschino» en la obra y lo que pudo aprender en ella.

Sintetizando lo ya publicado por Labó y Poleggi, podemos recordar que de 1559 a 1562 hay, básicamente, suministro de materiales para la construcción (piedra, cal, ladrillos), ejecución de fosos y provisión de pizarra para revestimentos y escaleras, siendo el arquitecto Bernardo Spazio, quien, a finales de 1563, aparece junto a Bernardino Cantone como árbitro en los precios de los materiales. En 1564 se cita ya a Juan Ponzello como arquitecto, se suministran cañerías de cerámica, se cierra la obra de madera del techo ${ }^{66}$ y Antonio Carabio suministra pizarra para escaleras (especificándose que la escalera principal tendrá como modelo la del palacio de Angel Juan Spinola en Strada Nuova, obra de Bernardo Cantone) y marcos de puertas.

En 1565 aparece el Bergamasco interviniendo en los trabajos decorativos, pues en agosto de ese año, Antonio Carabio contrata la portada interior del salón principal, que construirá en piedra negra del Promontorio ${ }^{67}$, y en septiembre, Agustín y Antonio Augustallo se comprometen a hacer el balcón de mármol de la sala principal que deberá abarcar las tres ventanas de la parte de mediodía, harán balaustres, ménsulas, cornisas y pilastrillas ${ }^{68}$. Ambos trabajos — portada y balcón - deberían hacerse según modelo entregado a los contratantes y que seguramente fue hecho por el Bergamasco, a cuyo juicio se somete el pago en ambos casos. Seis meses después de aparecer Castello en la obra, el 20 de marzo de 1566, se firma contrato con Battista Perolli para la pintura de las cuatro fachadas del palacio.

Por el contrato sabemos que la pintura se ha de hacer, de claro y oscuro, según el modelo dibujado por el mismo Perolli. La obra se ha perdido pero nosotros la conocemos gracias al grabado del libro de Rubens (fig. 5). La decoración realizada por Perolli es estrictamente arquitectónica $\mathrm{y}$, como se ha subrayado numerosas veces ${ }^{69}$, repite en pintura la estructura arquitectónica de Alessi para la fachada principal de la villa Cambiaso, imitando incluso la balaus-

${ }^{65}$ Poleggi, Ennio: Strada Nuova, una lottizzazione del Cinquecento a Genova, Genova, [1968] ed. 1972, especialmente pp. $172-174$.

${ }_{66}$ El documento, inédito hasta ahora, es de fecha 29-3-1564 y en él, Baptista de Grimaldis confiesa haber recibido de Dominico Monteverde, bancalario, q. Baptista, 330 libras y 14 sueldos genoveses, correspondientes a la devolución de un préstamo de trescientas libras hecho por Grimaldi en el año de 1562, y a los gastos correspondientes de estos años de unos solares que Monteverde entregó como garantía.

Como se recordará, en Génova era bastante habitual, que el propio comitente de una obra - generalmente banquero él mismo- prestase al contratista, cuando éste carecía de fondos, la cantidad de dinero necesaria para hacer frente a la garantía requerida para asegurar el cumplimiento de lo pactado. El contratista a su vez, hipotecaba bienes de su pertenencia, entregándolos al prestamista y, al terminar la obra, se hacía la liquidación de gastos e hipoteca. Así pues, en el documento ahora revisado, se liquida el préstamo indicando que doscientas libras corresponden al precio de la manufactura del techo de la villa de Grimaldi en Sampierdarena, ocho libras y doce sueldos al de la fabricación de una «giroxie» de madera, para su palacio genovés y el resto, hasta completar las 330 libras y 14 sueldos, se entrega en dinero contante, devolviendo Grimaldi los solares a Monteverde. (A.S.G. Not. Carosso, f. 3, $\mathrm{n}^{\circ} 2052$ ).

67 A.S.G., Not.Carosso, f. 3, n 2052, citado por Labó (ob. cit., 1925). Así son también las otras seis puertas menores de las paredes laterales. El reverso de la principal, que da a la logia, es de mármol con coronamiento de estucos, sin duda diseñados por el Bergamasco (véase más abajo).

68 (A.S.G. Not. Carosso, f. 3, $\mathrm{n}^{\circ}$ 2052, el documento es citado por Labó (ob. cit., 1925). Según él, el balcón estaba en mal estado en 1925 y la balaustrada había sido sustituida por un parapeto de mampostería (ibidem, p. 276). Actualmente puede verse un balcón similar al del lado norte que se hizo a imitación de éste. El número y descripción de las piezas que se hace en el documento, coincide plenamente con lo que hay en la actualidad.

${ }^{69}$ Labó, ob. cit., 1925; Ciliento, Bruno, Villa Grimaldi «Fortezza», Genova 1979; Boccardo, Piero,L'esordio della facciata dipinta nelle ville genovesi del Cinquecento: rapporti tra commitenza e iconografie, en Facciate dipinte, conservazione e restauro. Atti del convegno di studi, Genova 1982, pp. 241-244; Boggero, Franco, La struttura dipinta: la trattatistica, i modelli locali en Genua picta. Proposte per la scoperta e il recupero delle facciate dipinte, Genova 1982, pp. 57-65. 
trada del coronamiento alessiano y variando únicamente algunos elementos decorativos como los enmarques de las ventanas, los sillares marcados en la parte inferior, y el zócalo corrido de la planta noble con recuadros en relieve, según el gusto de Castello. En el mismo contrato se incluye la realización de un busto, retrato del comitente, que Labò dice no haber encontrado en su tiempo. El precio de la pintura se establece en 200 libras genovesas, quedando a voluntad del comitente el pago de una demasía si es de su agrado y dejando al acuerdo de comitente y escultor el precio del busto, una vez terminado ${ }^{70}$.

En el mes de agosto del mismo año Perolli se compromete a realizar el balcón de la logia de la planta noble, en la fachada norte del palacio (fig. 6). Se indica que ha de ser como el ya realizado por los hermanos Augustallo - como hemos visto anteriormente-, cuyo trabajo había dejado muy descontento a Grimaldi, no por el diseño sino por la manufactura, como se hace constar en el nuevo contrato. Esta vez el documento es aún más minucioso, haciendo constantemente referencia al modelo adjunto (perdido), detallándose número y medidas de cada una de las piezas - que corresponden exactamente con las conservadas en la actualidad-e indicando la obligación de hacerlas iguales a las del balcón de la fachada sur ${ }^{71}$. La terminación del trabajo queda, como en el caso de los Augustallo, a juicio de Francisco Pallavicino, quien puede aumentar el pago final a Perolli. Testigo del contrato es Castello ${ }^{72}$, quien, como vemos, trata de afianzar a Perolli en el servicio de Grimaldi y en la obra de Sampierdarena.

\footnotetext{
${ }^{70}$ Por su interés transcribimos el contrato no transcrito íntegramente nunca: Promissio et pactum de pingendo et alia. In nomine Domini Amen. Magister Baptista de Perolis quondam Stefani, pintor [sic]... promissit et convenit M.co.Domino Baptiste de Grimaldis, quondam M.ci. D.Jeronimi,... pingere pallacium seu domum dicti M.ci D.Baptiste, sittam in villa Santi Petri Arene, videlicet quatuor faciatas ipsius de foris restantes, modis, formis, qualitatibus et condicionibus infrascriptis, vulgari sermone exprimendis ad requisicionem dicti magistri Baptiste et de partium voluntate. Et primo, pingere le quatro faciate del palacio e caza di detto M.co Sig.Baptista, sitta in la sua villa de Sancto Petro de Arena, sotto sue confine, de pintura chiamata chiaro et scuro, de la forma e modelo convento fra esse parte, designato per esso maestro Battista, ben veduto et considerato, che serà sottoscripto de mano di me notario infrascripto, che resterà apresso detto M.co Sig. Baptista, per haverlo deto maestro Baptista, sempre li piacerà per vederlo cum tute requadrature, simile al disegno in tuta bellessa et perfectione, così del laborerio como di tuto lo atresamento et acomodamento, al quale laborerio detto maestro Baptista sia obligato, como promete dar principio, sempre che serà da detto M.co. richiesto. Et così, appresso a esso laborerio perseverare ogni giorno serà da lavoro et poter lavorare sino serà a perfectione... Et questo per pretio et mercede de libre ducento di moneta di Genua. Et di più resta in arbitrio di deto M.co Sig.Baptista de voluntà di detto maestro Baptista, finito et perfecto serà il laborerio perfectamente di ogni perfetione debita che resta a satisfactione di detto M.co. Sig. Baptista, quale harà da fare secondo la indigentia far preparare li ponti, a ciò possia lavorare et compire lo bizogno infra pagamento de la quale. Et di un busto marmoreo de la figura et retracto di esso M.co Sig. Baptista per il pretio di esso busto che convenirano insieme esso M.co Sig. Baptiste et maestro Battista. Detto maestro Baptista confessa havere habuto et receputo, come in vero ha receputo, libre cento de moneta de Genua, in presentia di me notario et testimonii infrascripti, dacti et a conto di dette libre ducento et del pretio di detto busto, che convenirano como di sopra. Et le restante libre cento et il pretio di detto busto conveninendo, il deto M.co Sig. Battista promete a detto maestro Battista, presente et acceptante pagare di tempo in tempo, secondo il lavoro sarà fatto, sino a lo integro pagamento, però perfecto detta opera de la pintura predetta et detto busto... Actum Janue, videlicet in camera salle pallacii dictiM.ci D.Baptiste, deversus viam publicam, sittam in contrata Sancti Francisci, anno Dominice Nativitatis Millesimo quingentesimo sexagesimo sexto, indicione octava secundum Janue cursum, die vero mercurii vigesima marcii in terciis, presentibus testibus...vocatis et rogatis. (A.S.G. Not. G.B.Carosso sc. 230, f. 3) Labó menciona el documento en 1925 (ob. cit., p. 272)

${ }^{71}$ Labó dice que los balaustres empleados en la villa Grimaldi son de forma insólita en Liguria «netamente lombardos»(ob. cit.,1925, p. 275). Como hemos visto anteriormente el modelo sería seguramente de Bergamasco, y Perolli, en este caso, se limita a copiarlo.

72 Promissio et pacta pro laborerio. In nomine Domini Amen. Magister Baptista de Perrolis de Clema quondam Stefani, sponte... promissit ac promitit Magnifico Domino Baptiste de Grimaldis... fabricare ser frabricari facere ad pallacium seu fabricam domus ville dicti Magnifici D. Baptiste, sitte in villa Santi Petri Arene, ad faciem tramontanam, pogiolum marmolreum, marmoribus Carrarie bonitatis et pulcritudinis ut mellius esse et reperiri poterit, modo instrumento vulgari sermone exprimendo, cioè, uno pogiolo di marmore di Carrara de la megior sorte, bontà e bellessa si potrà trovare... a lo piano de la salla grande, verso tramontana, il quale debia essere di longessa tanto che capisca li trei vani de li archi et più uno parmo per parte, donforme al disegno chje serà infilsato in lo presente instrumento... il quale pogiolo harà da essere largo fora del vivo de li pilastri o sia il muro da basso, parmi cinque fora de la muragia, cioè il piano de le lapide quale in esso pogiolo si harano da metere, che doverano essere numero octo, le gonture de le quale verano a restare ne li loci del disegno, dove resta fata una croce per ogni loco sopra li modilioni sopra esse lapide nel loco de le croci dopie, non removuto il detto di sopra, anchora che si dupliche la croce, le haverà da essere li soi pilastreti che haverano da sustentare la cornice di
} 
En febrero de 1567 se acondiciona el terreno lindante de la villa de Esteban Lomellino, que Grimaldi ha comprado, y que desea igualar con el suyo para cuando se cultive, y se construye un muro de cerramiento, todo bajo la dirección de Juan Ponzello ${ }^{73}$, el tercero de los arquitectos que aparecen y que junto con Cantone y Spazio formaban el equipo de Alessi en Génova.

En el mes de marzo se contrata con Andrés y Bautista de Carona la decoración de estuco de la logia de ingreso al salón principal. Esta obra, muy importante y que se conserva en la actualidad (fig. 7), consta de diferentes partes, para las cuales se entregan dibujos separados: uno para la bóveda, otro para las cuatro paredes, y un tercero para «uno busto et arma, cum ornamenti che resterà sopra la porta de la intrata de la sala» ${ }^{74}$ (fig. 8). Además, se especifica que los arcos de las cabeceras de la bóveda llevarán una «Historieta di relevo de maestro Lucho Camblaxio». Tres días después de firmar el contrato se suministra la cal necesaria para el estuque $^{75}$. El estudio de los estucos conservados y su relación con los realizados en la villa Cambiaso de Alessi, donde pintó Bergamasco, y con los hechos por los mismos estucadores en el palacio de Tobías Pallavicino, cuyo arquitecto fue Bergamasco, hizo que Labó adjudicase los dibujos perdidos y por tanto el diseño de toda la decoración -exceptuando lógicamente las historias de Cambiaso- a Castello ${ }^{76}$.

En mayo del mismo 1567, Abundio de Manziis se compromete a fabricar siete portadas de mármol, cinco para el palacio de Génova y dos para la villa (una para la entrada del pórtico y otra para la entrada del salón), según los modelos entregados y los maestros antelami Bautista

sopra, la quale cornice se intende doverà essere de pecii sete: tre di esse longe et intere quanto è il vacuo de li archi, le altre restanti quatro harano da essere longe per fare il compimento del bizogno et fra essi pilastreti nominati di sopra, li doverà essere li soi balaustri, quasi si passerano sopra le lapidi dette di sopra e substenterano le cornice del parapecto, cioè le cornice dette di sopra. Il numero di essi balaustri doverano essere tanti di numero e largi l'uno da l'altro, quanto si farà capace per disegno si risolverà esso Magnifico Signor Baptista. Sotto lo piano de le dette lapide si haverà a fare becheli numero sei longi fora del muro parmi quatro e mezo sino in 5 , secondo serà necessario et più dentro dal muro, quanto è grosso lo pilastro de li archi, in lo locho che resta sopra disegno segnato de lettera $\mathrm{R}$ e più altri trei becheli longi parmi quatro in circa fori del muro, conforme a la proportione dentro del muro como li altri detti di sopra, nel loco sopra il disegno notato litera E e più si ha da fare becheli sei picoli, fori dal muro parmi doi e merzo in circa, dentro dal muro de parmi uno e mezo, quali becheli servano più per ornamento che per fortessa, che doverano essere messi como nel loco del disegno, notato da litera M. La grossessa de tuti essi becheli, così li longi como li curti, haverano da essere conformi quanto serà necessario a proportione de lo altro pogiolo messo in opera a la facia di mezzogiorno a detta salla, la fatura sia il garibo de la ongessa fora del muro haverà da essere conforme a quelli del pogiolo detto di sopra messo in opera et cossì la forma de pilastreti, balaustri et cornice e lapide siano conformi a lo instrumento era intenuto da lo Augustino Augustalo e fratello, in opera cioè di sagome et ornamento, lo obligo de lo pogiolo ha fato, quale modelo e sagome restan apresso esso Mgnifico Signor Battista, sottoscripto de mia mano. Et ocurrendo al detto maestro Baptista di variare qualche cossa, così ne li modigioni, como nel sofito delle lapide e cossì cornice de balaustri, il detto maestro Baptista debia prima per disegni in carta, farne noticia al detto Magnifico Signor Baptista... intendendo però che esso laborerio harà da fare deto maestro Baptista debia essere megio lavorato di fatura che non resta lo altro misso in opera del quale ne resta molto discontento e questo per la manifatura e non perchè debia essere obligato a variacione alcuna del disegno e forma... che tuto reste... a iudicio però del Nobile messer Francesco Pallavicino... e questo per pretio e finito pretio de libre seicento cinquanta de Genua et da le libre 650 sino in libre 700, se debia stare a iudicio et declaracione di detto Nobile Messer Francesco Pallavicino... de le quali libre... esso maestro Baptista confessa havere havuto et receputo... libre trecento de Genua. Le restante libre 350 et più se sarà indicato esso Magnifico Signor Baptista harà da pagare... libre cento, sempre che esso maestro Baptista harà conduto a Genoa in sua butega o caza tute le lapide, marmori di ogni sorte... altre libre centro, laborato serà la metà di detta opera et lo restante de il precio predeto, una parte finito serà il laborerio et lo conpimento poi serà misso in lavore a tuta perfectione et bellessa. Et questo laborerio harà da fare deto maestro Battista como promete fato a tuta perfectione per tuto i meize de marzo proximo da venire con tuti li vincoli e pene, non observando, contenuto in lo inbstrumento facto cum Augustino Agustalo figiolo di Jo.Maria, rogato per me notario, lo anno passato a li 3 di setembre, che se harà in lo prsente da deto die... 1566 die veneris XXIII augusti... Testes magister Baptista de Castello quondam Johannis Marie de Bergamo... (A.S.G. Not. G.B.Carosso, sc. 230, f. 3. El documento es mencionado por Labò (ob. cit. 1925, p. 272).

73 A.S.G. Not. Carosso f. 3 n $^{\circ} 2052$, (Labó, ibidem).

${ }^{74}$ Esta puerta es la exterior del salón, cuya puerta interior, de piedra de Promontorio, hizo Carabio en 1565, como vimos más arriba.

75 Ambos documentos en A.S.G. Not. Carosso, f. 3, $\mathrm{n}^{\circ} 2052$

76 Ibidem, p. 277. 


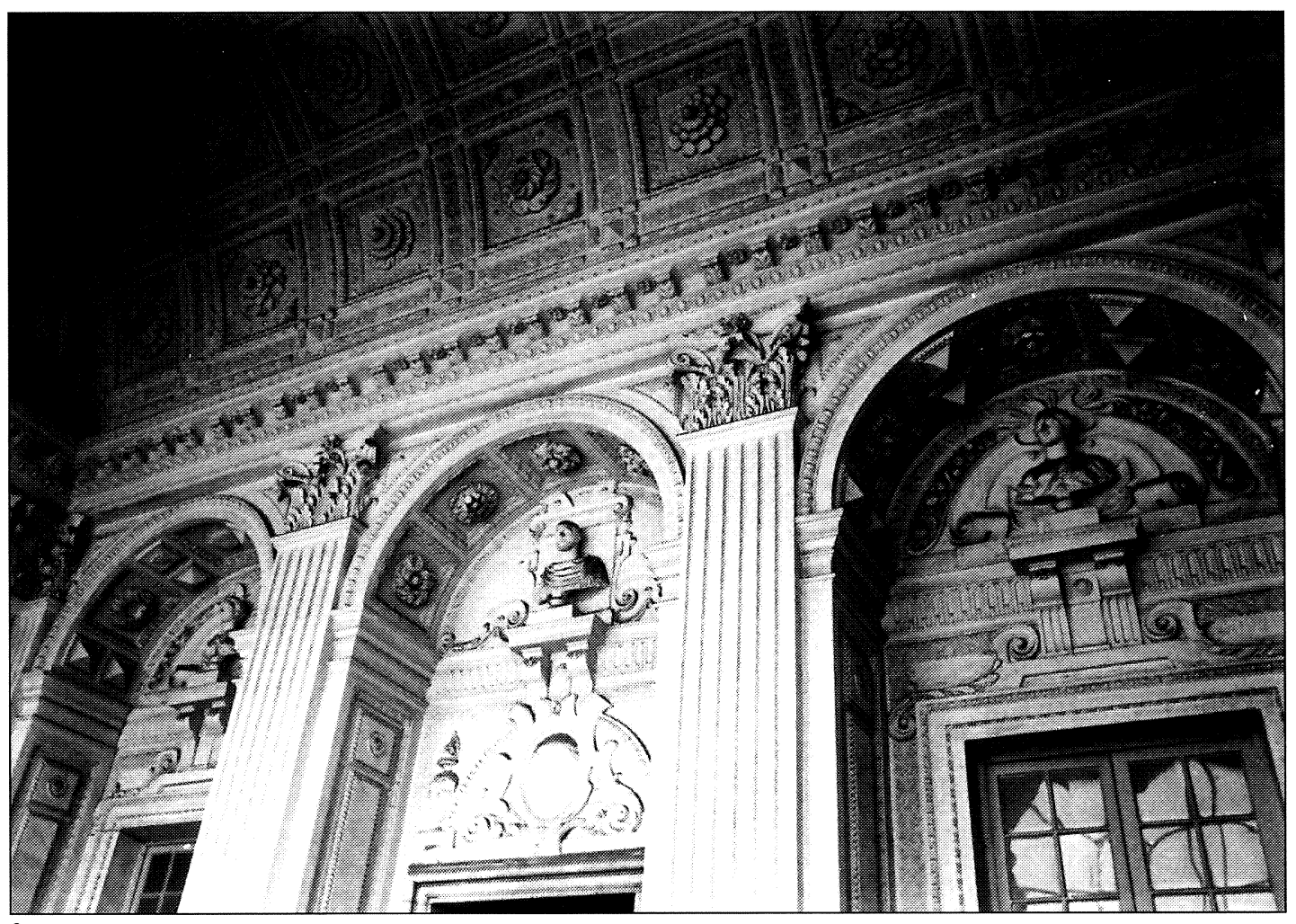

8
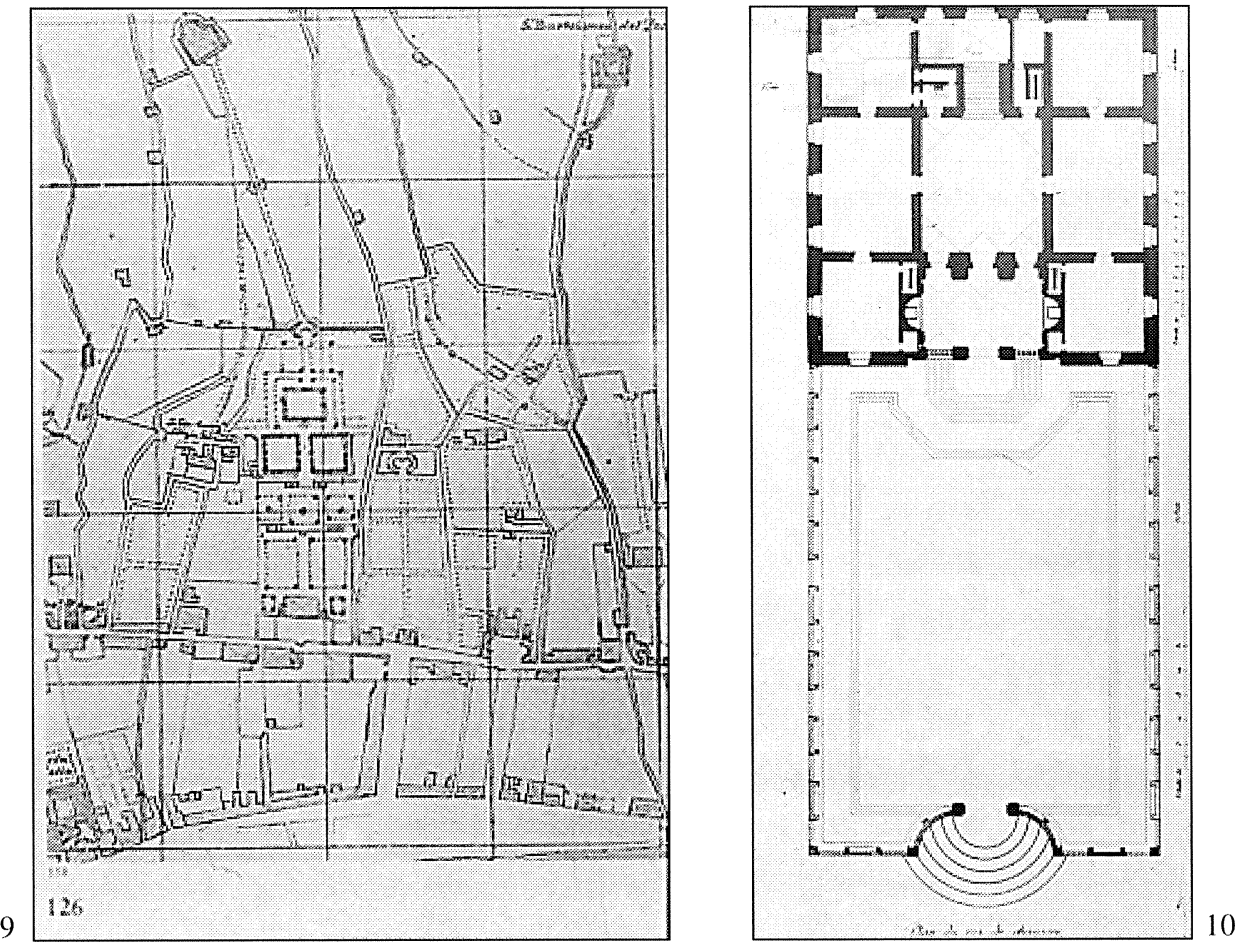

Fig. 8. Andrea y Bautista de Carona. Estucos de la logia de Villa Grimaldi. Génova, Sampierdarena. Fig. 9. Plano geométrico de Sampierdarena (s. XVIII). Génova. Archivio di Stato. Fig. 10. Villa Grimaldi. Planta según Gauthier (s. XIX) 
de Storaxio y Gasparino Storaxius se comprometen a hacer unos muros bajo la supervisión de Juan Ponzello ${ }^{77}$.

Las obras continúan en 1568 acondicionando de nuevo el terreno de la villa y demoliendo una torre, todo a las órdenes de B. Cantone ${ }^{78}$. En el mes de septiembre se inician una serie de trabajos en los que interviene de nuevo Perolli.

Para hacerlos se comprometen los maestros Juan de Magiis de Cabrio y Beltrán Fontana. El trabajo es bastante complejo y no ha sido estudiado anteriormente ${ }^{79}$. Se trata de una serie de construcciones que deben hacerse a la entrada de la plaza del palacio de Sampierdarena: logia, capilla, establo, almacén, caseta y una muralla hacia el mar. El modelo de estos trabajos lo da Perolli, pero la construcción se ha de hacer a juicio del arquitecto Cantone, que vigilará la obra. Para todo ello han de derribar la casa que perteneció al noble Pablo Ususmaris, comprada por Grimaldi, y aprovechar la piedra, el ladrillo y la madera para las nuevas construcciones. Se especifica además que las logias que han de hacerse en medio de la entrada de la plaza, han de ser con todos los ornamentos, y lo mismo en el ingreso de la escalera ${ }^{80}$.

Así pues el trabajo de Perolli en este caso sería parecido al que hasta entonces había hecho Bergamasco en lo referente a decoración, es decir, dar los modelos dibujados de las obras, entre los que se encontrarían los ornamentos de las logias del ingreso a la plaza y de la entrada de las escaleras, cuya ejecución sin embargo, quedaría a juicio del arquitecto Cantone, quien sin duda eligió a los maestros, puesto que él y Juan Lurago son sus garantes ante Grimaldi ${ }^{81}$.

De estas obras, no conservadas, se sabe poco. Labó dice, en 1925, que quedan restos de la decoración de la capilla «che è angustissima» ${ }^{82}$. Ciliento ${ }^{83}$ cita el mapa de Vinzoni de 1757 donde se ve el camino que llevaba directamente a la playa y que se abría entre terrenos propiedad de los Grimaldi. En el plano geométrico de Sampierdarena de finales del siglo XVIII (fig. 9) pueden verse los terrenos de la villa Grimaldi con construcciones a ambos lados del camino a la playa, que sitúan la villa en el contexto de estos últimos documentos. En la planta de Gauthier ${ }^{84}$ (fig. 10) puede verse el cerramiento de la plaza y la rampa de acceso, obras que, pensamos, corresponden a estos últimos trabajos para los que Perolli dio el modelo.

Así pues, una vez ausente Bergamasco, Perolli pasa a encargarse de la dirección de los trabajos de decoración en las obras de Grimaldi. No solamente da modelos, como acabamos de ver, sino que establece precios junto a los arquitectos Cantone y Chiona, como por ejemplo, en

\footnotetext{
77 A.S.G. Not. Carosso f. 3, $\mathrm{n}^{\mathrm{o}} 2052$

78 A.S.G. Not. L.Chiavari f. 15/287 (Poleggi,ob. cit., ed. 1972, p. 497).

79 Labó y Poleggi solo citan muy resumidamente el compromiso.

${ }^{80} \mathrm{El}$ documento es de 7-9-1568 y por él «Magister Johannes de Magiis de Cabrio de plebe Galerni, filius Francisci... et magister Beltrame Fontana quondam Baptiste, etiam de dicta plebe Galerni... promiserunt et convenerunt Magnifico Domino Baptiste de Grimaldis, quondam Magnifici Domini Jeronimi... facere et fabricare... laboreria infra dicenda, in loco Sancti Petri Arene, videlicet in ingresu platee domus magne seu palacii dicti Magnifici Domini Baptiste, sitte in dicta villa, videlicet, logiam, capellam, stabulam, feneriam, cameras, cazetam pro villis cum suis voltis et aliis necessariis dictorum laboreriorum, muragiam tendentem in longitudine versus mare quantum protendit villa dicti Magnifici Domini Baptiste. Et demum in omnibus prout continetur in modelo facto per magistrum Baptistam de Periolis, vissum et consideratum per dictos magistros Johannem et Beltrame... Et laboreria predicta promisetunt ipsi magistri... facere bene... iudicio magistri Bernardini de Agusto quodam Tadei... Et pro ipsis laboreriis faciendis teneantur ipsi magistri Johannes et Beltrame prout promiserunt... diruere se dirui facere, expensis ipsius, domum aquisitam per ipsum Magnificum D. Baptistam, que fuit quondam nobilis Pauli Usumaris..

Quod respectu logie faciende in medio ingresus platee dicti Magnifici D. Baptiste, erunt facienda aliqua ornamenta. Et similiter in ingresu scalarum ac aliis laboreriis... dictis magistris presentibus... iudicio dicti magistri Bernardi de Agusto et mei Notarii infrascripti... stare promiserunt... (A.S.G. Not.G.B.Carosso sc.230 f. 3).

${ }^{81}$ Marco de Maggi era yerno de Cantone y seguramente familiar de Juan de Magiis y tanto Fontana como Lurago y Bernadino de Novo, que figura como testigo, son paisanos, y colaboradores asiduos de Cantone en sus obras, como anteriormente lo habia sido Bergamasco. (Véase Poleggi, ob. cit. ed. 1972 p. 110-11

82 Ob.cit. p. 278.

83 Ob. cit. p. $4-5$.

${ }^{84}$ M.P. Gauthier, Les plus beaux édifices de la ville de Gênes e de ses environs, Paris 1818.
} 
mayo de 1569, cuando Antonio Carabio contrata los mármoles y piedra de Finale para columnas y otros elementos de los palacios de Grimaldi en Génova y Sampierdarena ${ }^{85}$, o trata directamente con los ejecutores materiales de los trabajos, como veremos seguidamente.

A finales de 1570 se debían estar dando los toques finales a la plaza de la villa, pues de nuevo se contrata con el maestro Abundio de Manziis, piedra de Finale para hacer la rampa de acceso al palacio de Sampierdarena desde la plaza ${ }^{86}$. Dentro de los trabajos de acondicionamiento de terrenos y entorno de la villa debieron de entrar los jardines, y a ellos sin duda se destinaron las esculturas contratadas en 1571.

En el mes de junio de este año se contrata con Rafael de Michaelis, florentino, una escultura de mármol de Carrara de 1,80 metros aproximadamente, cuya iconografía no se especifi$\mathrm{ca}$, pero sí se indica que ha de ser conforme a una estatua de Baco que el escultor vende igualmente a Bautista Grimaldi. El Baco queda depositado en casa de B. Perolli hasta que el escultor lo termine debidamente y el cremasquino actúa como intercesor del escultor y fija para el Baco el mismo precio que para la estatua objeto del contrato (47 escudos de oro) ${ }^{87}$.

Desde 1571 a 1574 no hemos encontrado documentación sobre obras destinadas a la villa Grimaldi, pero no hay duda de que J.B.Perolli siguió ejerciendo la dirección y supervisión de los trabajos relacionados con la decoración de la villa, en la que se seguía trabajando en 1574, probablemente en el acondicionamiento de logias, rampas o escaleras con baluastradas de los jardines. Unos meses antes, en mayo, los mismos maestros habían contratado con Bernardo Grimaldi la fabricación de balaustres, basas, cornisas y pedestales de piedra, según el modelo del maestro Bautista Cremasco. En agosto de este último año, los maestros Antonio Galleto y Tomás de Avancino contratan la fabricación de ocho basas y dos «conchetas» [sic] de piedra de Finale según modelo de Bautista de Perolis de Crema que se han de entregar en la villa de Sampierdarena, siendo su aval Agustín de Augustallo, quien también lo es en el préstamo que les hace Bautista Grimaldi para garantizar este compromiso y en el que Bautista Perolli actúa de testigo ${ }^{88}$.

85 A.S.G. Not. Leonardo Chiavari sc. 287 f. 17.

${ }^{86}$ A.S.G. Not. G.B. Carosso f. 3, $\mathrm{n}^{\circ} 2052$.

${ }^{87}$ El documento dice así en sus partes principales: 1571, 21 iunii.In nomine Domini Amen. Rafael de Michaelis scultor florentinus, quondam Michaelis... promissit et convenit M.co D. Baptiste de Grimaldis quondam D. Jeronimi... facere et fabricare statuam marmoream de qua infra, videlicet che promete di fare e fabricare a tute sue speze, così del marmoro, come de le manifature domandate.

Serà de marmoro de Carara in ogni bontà, belessa e perfectione, che resta più bella, de la longesa de parmi sete e quarti trei conforme a qualla di Bacho e megio lavorata che la figura infra dicenda del Bacho. Et demum in ogni bellessa a satisfatione del detto signor Battista, la quale promete di fare e consignare a detto signor Battista o agenti per lui, in la presente cità, a la stancia de la abitacione del detto Raffaello, dove lavorerà detta statua, fra il termine de mexi cinque proximi da venire. E questo per pretio e nome de pretio de scuti quaranta sete e mezo d'oro in oro de ittalia... et che la doverà consignare ogni contradictione removuta...

Et per le predette cose essere observate, intercede et manleva in Baptista clemascho. quondam Stefano, presente, che renuntia la ragione de lo principale. Et de più esso Rafaelo ha venduto a detto Signor Baptista, licet absente et per lui me notaro aceptante, un'altra statua de marmoro lavorata per la figura de Bacho, quale adesso resta in casa di detto maestro Baptista Clemascho, quale non resta anchora intus perfectamente finita.

Et quale detto Rafaelo promette finire in ogni bel possibile.

Et quella consignare a ogni sua volontà. Et così detto maestro Baptista anchora promette a quel serà, per pretio de scuti 47 d'ro in oro de Ittalia, datti pagati e consignati per Luca Picembono, caserio de detto Sig. Baptista, ... Actum Janue in contrata Sancti Francisci... (A.S.G. Not. G.B. Carosso, sc. 230, f. 3).

${ }^{88} \mathrm{El}$ primer documento dice así: Promissio.In nomine Domini Amen. Thomas Avancinus filius Marci...et Antonius Galletus quondam Georgii picapetrum... promisserunt et promittunt Il.D.Baptiste de Grimaldis quondam D. Hieronimi... fabricare prefato Ill.D.Baptiste, vasa octo petre Finarii et conchetas duas, ut aiunt, etiam petre Finarii, mensure sortis et qualitatis iuxta modellum existentem penes magistrum Baptistam de Perolis de Crema quondam Stefani... Et que quidem vasa et conchetas, promittunt fabricare et consignare prefato Ill.D.Baptiste, intra diem decimam octobris proxime venturi in Sancto Petro Arene, in villa prefati Ill.D.Baptiste... Pro pretio, videlicet; vasa, ad racionem librarum quatuordecim monete Genue singula et conchete, ad racionem librarum duodecim singula... et pro eo, tam pro observacione presentis contractus quam pro dictis libris sexaginta, intercessit et fideiussi Augustinus de Augustalis quondam Johannis Marie picapetrum... Actum Genue... anno a Nativitate Domini Millesimo quigentesimo septuagesimo quarto... die veneris XIII augusti...

El segundo documento es del 12-3-1574 (ambos en A.S.G. Not. Giacomo Ligalupo, sc. 451, f. 5). 
Unos meses antes, en mayo, los mismos maestros habían contratado con Bernardo Grimaldi la fabricación de balaustres, basas, cornisas y pedestales de piedra, según el modelo del maestro Bautista Cremasco, y balaustres de mármol como «los que están trabajando en la villa de San Pierdarena del Sr. Baptista Grimaldo», en cuya villa se habían de entregar ${ }^{89}$.

En ocasiones han sido atribuidas a Perolli los frescos que decoran las salas de la villa, pero, por lo que hemos podido estudiar en las pinturas mejor conservadas, y lo que conocemos del palacio del Viso, creemos que los frescos no son suyos sino de los Calvi (especialmente las historias de la Sala de Troya, Sala de Historias romanas, Sala de batallas y Sala de la Fama), y que debieron realizarse después de 1574, cuando Perolli ya había partido para España. No obstante y dadas las fechas, es muy probable que, como había sucedido en otras ocasiones por ejemplo en el mismo palacio Grimaldi de San Francisco- los esquemas generales de decoración de algunas salas sí se deban a él ${ }^{90}$.

El mismo año en que Perolli comienza a trabajar en la villa Grimaldi y un mes después de haberse comprometido a hacer el balcón de la loggia del salón, el 26-9-1566. el cremasco ofrece garantía a Juan Bautista Spinola por un préstamo de 200 libras hecho anteriormente al Bergamasco, en ese momento ausente ${ }^{91}$, compromiso al que sin duda se hace referencia cuando Perolli a su vez, garantiza la devolución del préstamo de 25 libras hecho a él mismo por Mateo de Semino el 12-4-67 ${ }^{92}$.

Durante algún tiempo, después de la partida de Castello, Juan Bautista Perolli continuará alternando el trabajo entre las obras dejadas sin terminar por Bergamasco y las contratadas personalmente por él, hasta asumir totalmente la dirección de las obras decorativas de Juan Bautista Grimaldi, como hemos visto en la villa de Sampierdarena y como continuaremos viendo en otros casos.

\footnotetext{
89 Este Bernardo Grimaldo, hijo de Pablo, es un sobrino de Nicolás Grimaldi «el monarca» que preparaba por esos años su palacio de Strada Nuova. El documento en su parte fundamental dice así: 5-5-1574. Promissio laboreriorum. In nomine Domini Amen. Antonius Galletus, quondam Georgii et magister Thomas de Avancino, filius Marci, maior, etc. picapetrum... promisserunt et promittunt Nobili Bernardo de Grimaldis D. Pauli... facere... quaranta otto balaustri di pietra di Finaro, alti parmi $31 / 2$ e grossi doi terzi a palmo di doi vasi e più palmi cento otto di cornice della medesima pietra grossa mezzo palmo e larga un palmo e mezzo, lavorate e polite come ha de mettersi in lavoro. E più pedestalli a $n^{\circ}$ sei, conforme al modello datoper maestro Baptista cremascho. E più balaustri $n^{\circ}$ sedesi di marmarmo bianco, della grossezza et altezza di quelli sono in lavoro in la villa di San pier d'Arena dal sig. Baptista Grimaldo. E più balaustri quarantotto delle pietre che a loro si dirà quali hanno d'essere di doi vasi et de grossezza de mezzo palmo... et promittunt finire... et consignare in villa Sancti Petri Arene, videlicet in villa dicti D. Baptiste de Grimaldis... Et pro eis, pro predictis omnibus intercessit et fideiussit magister Thadeus Ursolinus marmararius quondam Domninici... Actum Genue... Presentibus... (A.S.G. Not. Giacomo Ligalupo, sc. 451, f. 4).

90 Véase más arriba nota 29.

${ }^{91}$ La noticia en Alfonso, Luigi: «I Carlone a Genova», La Berio (1977), pp. 87-88, aunque referida la deuda a Daniele Spinola da Luccoli por un préstamo del 25 de marzo. Probablemente se trate de los mismos documentos y de una confusión en la fecha y en el nombre del prestamista. Tanto el documento del préstamo como el de garantía de Perolli están en A.S.G. Not.P. Battista d'Andrea, sc. 409, filza 1. El primero testifica el préstamo «gratis et amore» de 200 libras genovesas por parte de Giovanni Battista Spinola q.Nicolai, las cuales promete devolver Castello en los tres meses siguientes. El segundo testifica que Castello no ha pagado y está ausente, por lo que Perolli se compromete a devolver a G.B. Spinola las doscienteas libras «en paz y sin litigo» en los próximos seis meses. Como se recordará Castello había trabajado en el palacio de J.B. Spinola en Strada Nuova (véase Poleggi ob. cit. 1972, p. 249-261), lo que justificaría el préstamo sin intereses. La falta de pago apoyaría la teoría de Soprani (ob. cit., I, p. 406) de que Bergamasco vino a España huyendo de sus numerosas deudas.

92 A.S.G. Not. Giacomo Villamarino, sc.190, f. 17 (Manuale). Detrás de una lista de deudores que lleva fecha 11-4-67 y de varios asientos con reconocimiento o pago de deudas de fecha 12-4, hay uno de Baptista de Perolis de Crema, quondam Stephani, en el que éste se compromete a pagar a Mateo de Semino quondam Francisci, 25 libras genovesas prestadas ante el notario, pero estableciendo la condición de que «si Baptista de Castello, pictor, scribet ipsi Matheo, quod faciat bonum quandam promissionem factam per dictum de Perolis pro dicto Baptista de Castello, quod, talli casu, dictus Matheus promisit contraponere predictas L. 25 pro dicto Baptista de Castello. sub. etc. et dummodo scribat infra menses duos».
} 